\title{
Research on a China 6b Heavy-duty Diesel Vehicle Real-world Engine out NOx Emission Deterioration and NOx Correction for Humidity and Temperature using On-board Sensors and Big Data Approach
}

\section{Peng Li ( $\square$ leepeng@whut.edu.cn )}

Wuhan University of Technology https://orcid.org/0000-0002-9672-2109

Lin Lü

Wuhan University of Technology

\section{Research Article}

Keywords: Heavy-duty diesel vehicle, engine out NOx emission, deterioration factor, NOx correction for humidity and temperature, big data

Posted Date: March 8th, 2021

DOl: https://doi.org/10.21203/rs.3.rs-298580/v1

License: (c) (1) This work is licensed under a Creative Commons Attribution 4.0 International License.

Read Full License 


\title{
Research on a China $6 b$ heavy-duty diesel vehicle real-world engine out NOx emission deterioration and NOx correction for humidity and temperature using on-board sensors and big data approach
}

(1)

\author{
Peng $L i^{1, *}, \operatorname{Lin} L \ddot{u}^{I}$ \\ ${ }^{1}$ School of Energy and Power Engineering, Wuhan University of Technology, Wuhan, 430063, China \\ ${ }^{*}$ E-mail:leepeng@whut.edu.cn
}

\begin{abstract}
China VI standard proposed higher requirements for durability of heavy-duty diesel vehicles emissions. Previous research which took advantages of both on-board sensors and big data approach to get the NOx deterioration factor was rather scarce. This paper used big data approach to study the deterioration of engine out NOx emission based on $254,622 \mathrm{~km}$ operation data getting from the on-board sensors or ECUs. Meanwhile, a formula for on-board NOx correction for ambient humidity and temperature had been fitted. The analyses revealed that engine out NOx would not be deteriorated during the useful life or even longer (deterioration factor was $1.014 @ 700,000 \mathrm{~km}$ ). For a steady working condition, the engine out NOx mass flow $(\mathrm{g} / \mathrm{h})$ is negatively linearly correlated with absolute humidity $\left(\mathrm{R}^{2}=0.997\right)$. If $\mathrm{Ha}$ was lower than $12 \mathrm{~g} / \mathrm{kg}$, Ha almost had no effect on engine out NOx concentration (ppm). Otherwise, there was also a negatively linear relationship between them $\left(\mathrm{R}^{2}=0.978\right)$. It is hoped that the methods and conclusions of this paper could provide some enlightenment for future NOx emission deterioration research.
\end{abstract}

\section{Keywords}

Heavy-duty diesel vehicle, engine out NOx emission, deterioration factor, NOx correction for humidity and temperature, big data

\section{Introduction}

On-road diesel vehicles produce a great amount of nitrogen oxides (NOx) worldwide, leading to deteriorating environment and increasing health issues (Anenberg et al., 2017; Cheng et al., 2019). The second national (China) pollution source census statistical result showed that heavy duty 
diesel vehicles accounted for $2.04 \%$ of the total number of motor vehicles, but the NOx emission accounted for $61.84 \%$ of the total vehicle NOx emission, $34.56 \%$ of the total mobile pollution sources NOx emission (China et al., 2017).

In the past few decades, increasingly stringent emission regulations have been adopted by many countries (e.g., Europe, US, Korea, Japan) (Grange et al., 2017; Wu et al., 2017). China had also issued "Limits and measurement methods for emissions from diesel fueled heavy-duty vehicles (CHINA VI)" numbered "GB17691-2018” in June, 2018. In China VI legislation, the requirement of useful life was increased, also for the first time the emissions warranty period was set. For instance, for the vehicles of category N3 with a maximum technically permissible mass exceeding $18,000 \mathrm{~kg}$, the useful life is $700,000 \mathrm{~km}$ or seven years, the minimum emissions warranty period is $160,000 \mathrm{~km}$ or five years, whichever is the sooner. Meanwhile, the minimum service accumulation period is 233,000km (GB, 2018; Economic Commission, 2010; European Commission, 2011).

Manufacture generally verifies whether the emissions durability of the engine meets the requirements of the regulations through the durability test. Since a urea-SCR catalyst with high activity and durability is critical for the NOx emission control, most studies focus on the deterioration of SCR catalyst. Vehicle aging and oven aging are usually used for the research of SCR catalyst deterioration. The vehicle aging method provides realistic conditions, however the process requires long durability testing time. Thus, the oven aging approach has been used as an accelerated aging method with the purpose of reducing the total duration of the test by thermally stressing the catalyst in a high temperature environment (De et al., 2017; De et al., 2018). In the aging process, periodically test was carried out on the engine bench to obtain the SCR conversion efficiency. Finally, a deterioration equation for SCR conversion efficiency was fitted (Zhang et al., 2018; McCoy et al., 2014; Schmieg et al., 2012).

The deterioration equation of SCR conversion efficiency can characterize the deterioration of tailpipe NOx emission only if there is no deterioration of engine out NOx emission. However, few previous studies have been carried out on the deterioration of in-use vehicles engine out NOx emissions. If the engine out NOx deteriorates significantly, the tailpipe NOx may also fail to meet the regulatory requirements even if the SCR conversion efficiency remains the same as the original state. Therefore, the study of engine out NOx deterioration also makes sense for NOx emission 
control.

On the other hand, as the NOx emission depends on ambient air conditions, the NOx concentration shall be corrected for ambient air temperature and humidity before analyzing the deterioration of engine out NOx emissions by using the data from the on-board NOx sensors (Krause et al., 1974; Hiromi et al., 1991; Pekula et al., 2003; Asad et al., 2012; Liu et al., 2015; Wang et al., 2018; Wang et al., 2019). Since few in-use vehicles were equipped with ambient humidity sensor, almost no study takes advantage of vehicle operation data to analyze the influence of ambient factors on engine out NOx emission. Furthermore, no study had given out a formula suitable for on-board NOx sensor for NOx correction for ambient air temperature and humidity.

In view of the abovementioned problems, before the durability test, ambient air temperature and humidity sensors were installed at the engine air filter on the tested vehicle. The real-time data was uploaded $(1 \mathrm{~Hz})$ to the cloud platform via telematics box (T-box). Based on the second-bysecond data obtained from the $254,622 \mathrm{~km}$ durability test, by using big data approach, this work was going to achieve the following goals:

- Getting the deterioration equation and the useful life deterioration factor (DF) of the engine out NOx for the tested vehicle;

- Fitting an ambient air temperature and humidity correction formula for NOx sensor.

\section{Materials}

\subsection{Tested vehicle}

A N3 category heavy-duty diesel vehicle (Figure 1(a)) which was type approved to the China VI (step B) standard and registered in August 2019 was used to perform the on-road durability test.

There are two on-board NOx sensors located at diesel oxidation catalysts (DOC) inlet for engine out NOx measurement and ammonia slip catalyst (ASC) outlet for tailpipe NOx measurement, respectively (Figure 1(b), Figure 1(c)). The main characteristics of the tested vehicle are summarized in Table 1.

The main operating route of the tested vehicle was the expressway between several cities (Shanghai, Suzhou, Hefei, Guangzhou, Shenzhen, etc.) in Southeast China (Figure 2). 


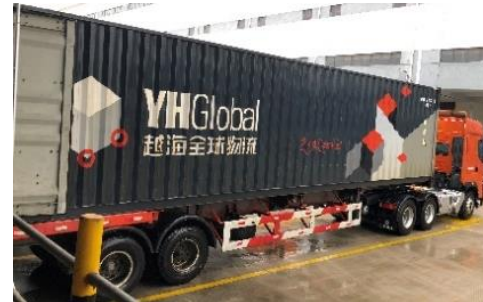

(a)

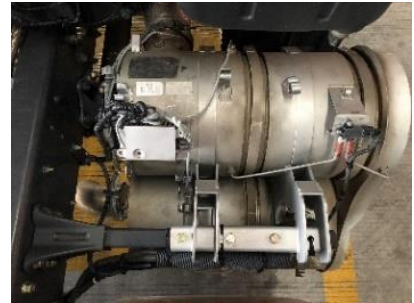

(b)

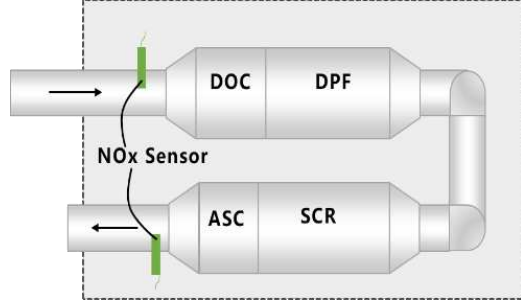

(c)

Figure 1. (a) Tested vehicle; (b) aftertreatment configuration (picture of real products); (c)

NOx sensors location and aftertreatment configuration (schematic plot).

Table 1 Summary of vehicle, engine, aftertreatment, fuel and DEF specifications.

\begin{tabular}{ll}
\hline Type of Vehicle & N3 (Long-Haul) \\
\hline Year of production & $7 / 2019$ \\
Type of engine & XX13600-60 \\
Maximum technically permissible mass & $48,800 \mathrm{~kg}$ \\
Engine rated power & $441 \mathrm{~kW}$ \\
Reference torque & $3000 \mathrm{Nm}$ \\
WHTC cycle work & $38.72 \mathrm{kWh}$ \\
Emission standard & China VI (step B) \\
Aftertreatment system & DOC+DPF+SCR+ASC \\
Fuel & China VI Standard \\
Diesel exhaust fluid (DEF) & Adblue (32.5\%) \\
Method of pressure charging & Turbocharging \\
Charge air cooling system & Intercooler \\
\hline
\end{tabular}




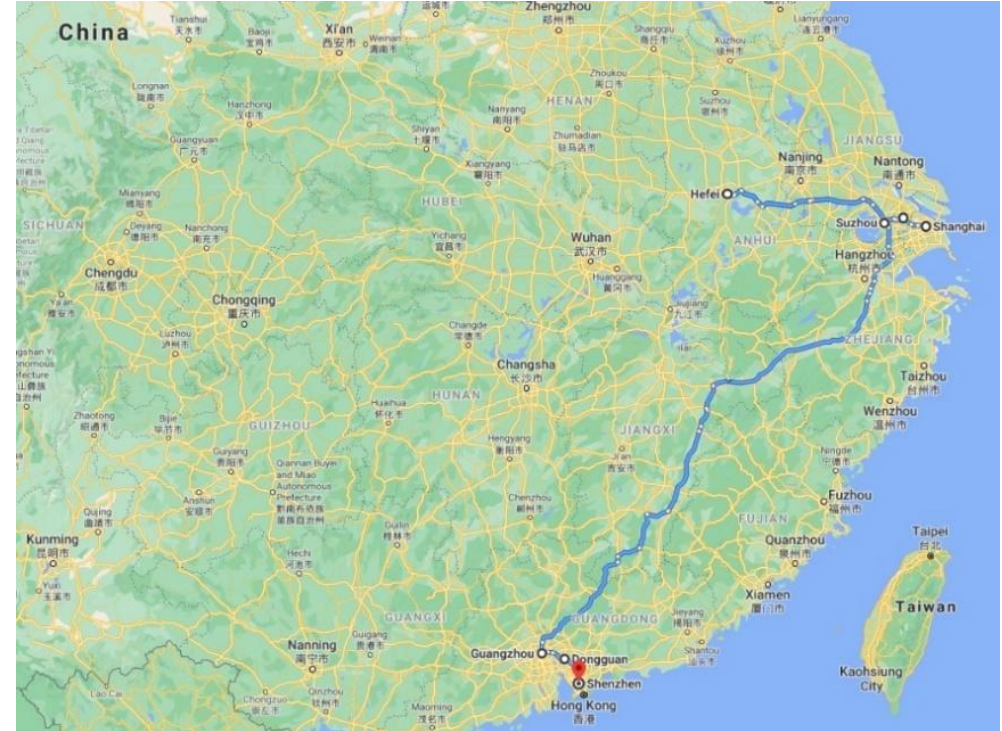

Figure 2 The main operating route of the tested vehicle

\subsection{Data acquisition system}

Data acquisition of durability test was based on the remote data acquisition system which included sensors (e.g. temperature sensors, pressure sensors), ECUs (e.g. EECU, VECU), telematics box (T-box) and cloud platform (Figure3). The communication between the ECUs and T-box was carried out through CAN (Controller Area Network) bus. T-Box encrypts and packs the data, then uploads the data packets to the cloud platform with $1 \mathrm{~Hz}$ frequency based on https protocol through its built-in wireless communication module. After receiving the data packet, the cloud platform analyzes, stores and visualizes it. Meanwhile, the cloud platform provides functions such as data retrieval, download, statistical analysis, API (Application Programming Interface) and so on.

The Parameters collected in the durability test including ambient parameters, vehicle parameters, engine parameters and aftertreatment system parameters were shown in Table 2. 


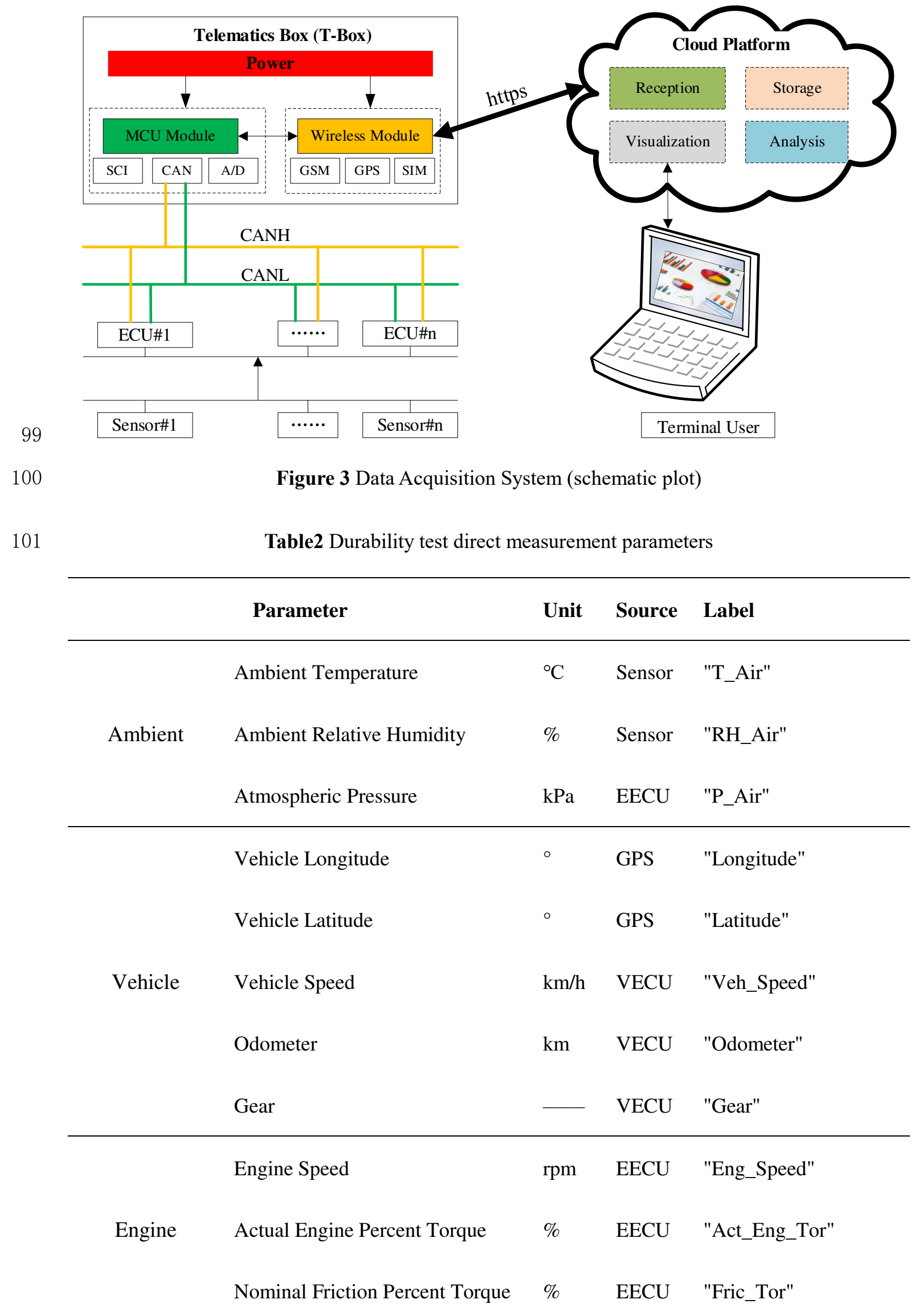




\begin{tabular}{|c|c|c|c|c|}
\hline & Throttle Opening & $\%$ & EECU & "Throttle_Opening" \\
\hline & Rail Pressure & $\mathrm{hPa}$ & EECU & "P_Rail" \\
\hline & Injection Timing & ${ }^{\circ} \mathrm{CA}$ & EECU & "Inj_Timing " \\
\hline & Fuel Consumption Rate & $\mathrm{kg} / \mathrm{h}$ & EECU & "Fuel_mRate" \\
\hline & Accumulative Fuel Consumption & $\mathrm{L}$ & EECU & "Acc_Fuel_Cons" \\
\hline & Fuel Tank Level & $\%$ & EECU & "Fuel_Level" \\
\hline & Intercooler Outlet Temperature & ${ }^{\circ} \mathrm{C}$ & EECU & "T_AirC_O" \\
\hline & Intercooler Outlet Pressure & $\mathrm{kPa}$ & EECU & "P_AirC_O" \\
\hline & Intake air Mass Flow & $\mathrm{kg} / \mathrm{h}$ & EECU & "Int_MassFlow" \\
\hline & Intake Valve Opening & $\%$ & EECU & "Int_Valve_Opening" \\
\hline & Coolant Temperature & ${ }^{\circ} \mathrm{C}$ & EECU & "T_Coolant" \\
\hline & Oil Temperature & ${ }^{\circ} \mathrm{C}$ & EECU & "T_Oil" \\
\hline & Oil Pressure & $\mathrm{kPa}$ & EECU & "P_Oil" \\
\hline & Engine Out NOx & ppm & Sensor & "EngOut_NOx" \\
\hline & DOC Inlet Temperature & ${ }^{\circ} \mathrm{C}$ & EECU & "T_DOC_In" \\
\hline & DPF Inlet Temperature & ${ }^{\circ} \mathrm{C}$ & EECU & "T_DPF_In" \\
\hline & DPF Pressure Drop & $\mathrm{kPa}$ & EECU & "P_Drop_DPF" \\
\hline Aftertreatment & SCR Inlet Temperature & ${ }^{\circ} \mathrm{C}$ & EECU & "T_SCR_In" \\
\hline system & SCR Outlet Temperature & ${ }^{\circ} \mathrm{C}$ & EECU & "T_SCR_Out" \\
\hline & Urea Injection Temperature & ${ }^{\circ} \mathrm{C}$ & EECU & "T_Urea_Inj" \\
\hline & Urea Consumption Rate & $\mathrm{mg} / \mathrm{s}$ & EECU & "Urea_Inj_Rate" \\
\hline & Urea Pump Pressure & $\mathrm{hPa}$ & EECU & "P_Urea_Pump" \\
\hline
\end{tabular}




$\begin{array}{lccl}\text { Urea Tank Level } & \% & \text { EECU } & \text { "Urea_Level" } \\ \text { Urea Tank Temperature } & { }^{\circ} \mathrm{C} & \text { EECU } & \text { "T_Urea" } \\ \text { Urea Concentration } & \% & \text { EECU } & \text { "Urea_Conc" } \\ \text { Tail Pipe NOx } & \text { ppm } & \text { Sensor } & \text { "Tailpipe_NOx" }\end{array}$

\section{Method}

\section{$103 \quad 3.1$ Method of engine out NOx deterioration analysis}

104 This paper used the method shown in Figure 4 to carry out the research. Firstly, we should get 105 the "Clean Dataset", "Basic Dataset" and "Analysis Dataset". Then, get the maximum odometer 106 (Odo_Max) without deterioration of engine out NOx. Finally, in the range of "Odo_Max", based on 107 the NOx sensor and ambient air temperature and humidity sensors, accomplished NOx correction 108 for ambient temperature and humidity and forecasted the deterioration factor (DF) of engine out 109 NOx throughout the useful life of the tested vehicle. 


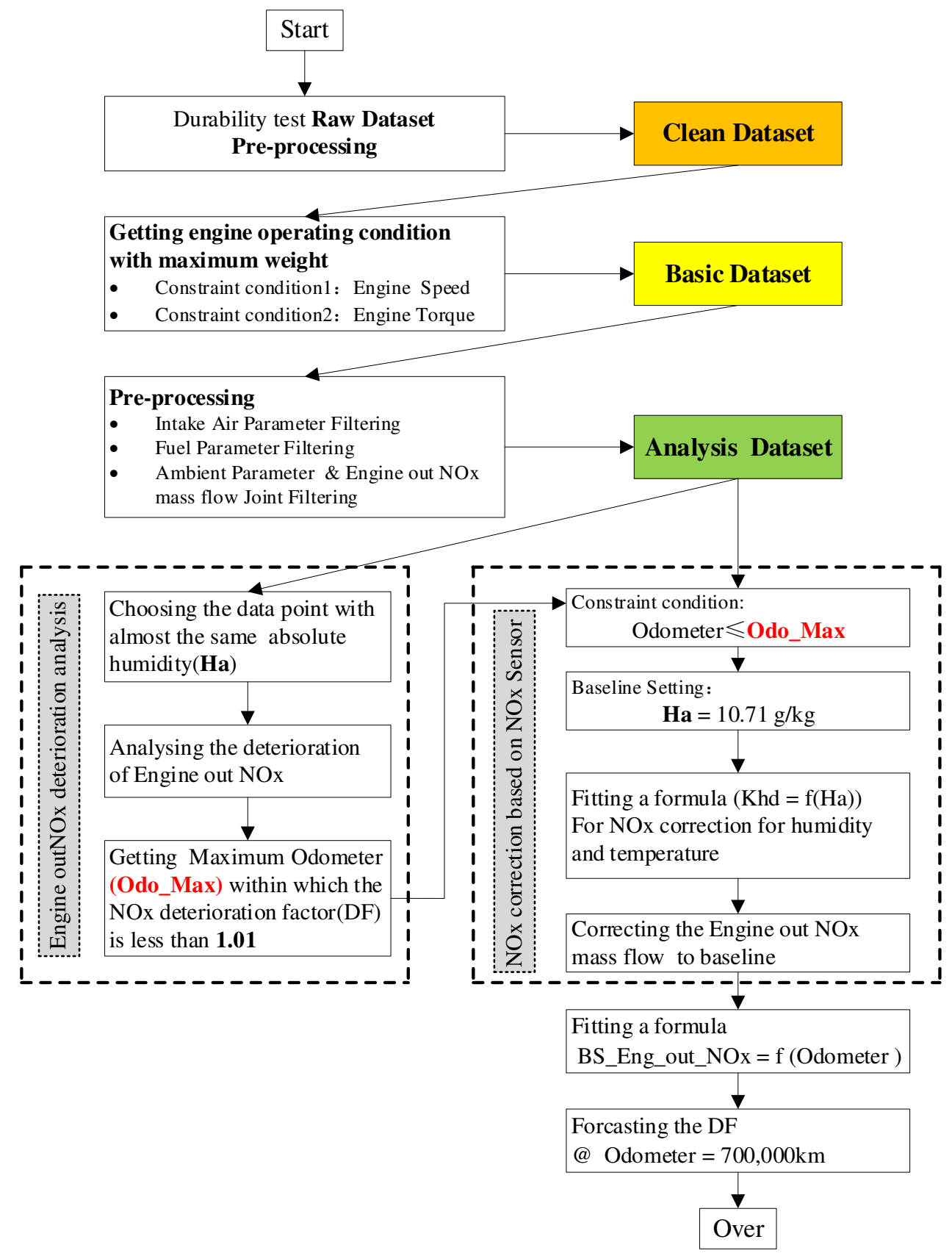

Figure 4 Method of engine out NOx deterioration analysis

\subsection{Data preprocessing}

Volume, velocity, variety, value, and veracity are the ' $5 \mathrm{~V}$ ' attributes of big data. Due to the low

114 value density of big data, it is necessary to preprocess the data before analyzing a specific issue. Typically, data preprocessing includes duplicates drop, NaN filling, outliers handling, derived

116 parameter calculation, normalization, feature selection, and so on (Luengo et al., 2020; Steffen et 
columns (features), which belonged to the tall skinny dataset. The "Raw Dataset" preprocessing for engine out NOx deterioration analysis mainly included outliers handling, derived parameter calculation and feature selection.

\subsubsection{Outliers handling}

The outliers of the datasets used in this paper can be classified into modifiable outliers and unmodifiable outliers.

\section{- Modifiable outliers}

Figure 5(a) shows the ambient temperature in the "Raw Dataset" with abnormal points. Figure 5(b) shows the modified ambient temperature. As we know, generally, ambient temperature would not suddenly severe change in a short time, so the pre-value or post-value both can be used as an alternative.

In this paper, the previous value fill method ("ffill" method in python) is used to deal with the modifiable outliers. In the same way, this method was also fit for the outliers of other signals which would not suddenly severe change in a short time, such as atmospheric pressure, longitude/latitude, fuel/urea level, odometer, etc.

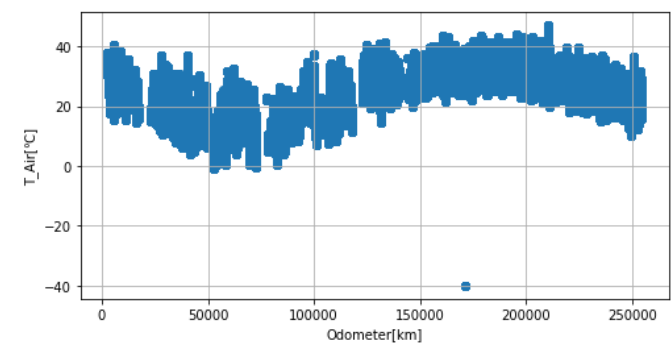

(a) Before preprocessing

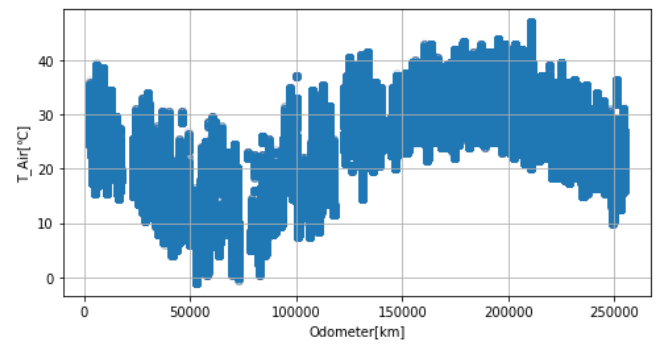

(b) After preprocessing

Figure 5 Demo for modifiable outliers preprocessing

\section{- Unmodifiable outliers}

As shown in Figure 6(a), the engine out NOx concentration in the "Raw Dataset" has many abnormal points which were less than zero. Since the engine out NOx concentration was related to the engine working condition, and for in-use vehicles, the engines usually operate in transient conditions, it is impossible to replace the abnormal points with the pre-value or post-value. Generally, for the high-thin datasets, the unmodifiable outliers can be directly deleted. Figure 6(b) shows the engine out NOx concentration without abnormal values. 
143 (such as fuel injection timing, fuel consumption, throttle opening, urea consumption rate, etc.) can be handled by the same way.

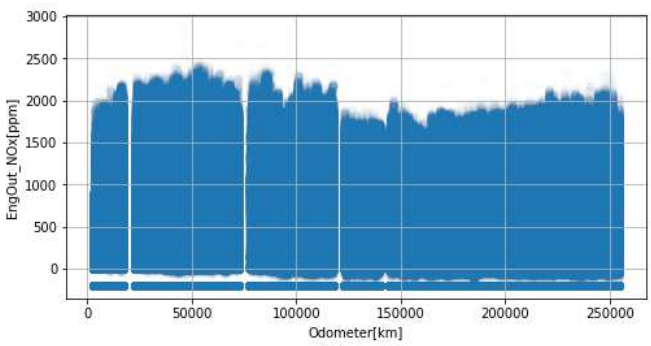

(a) Before preprocessing

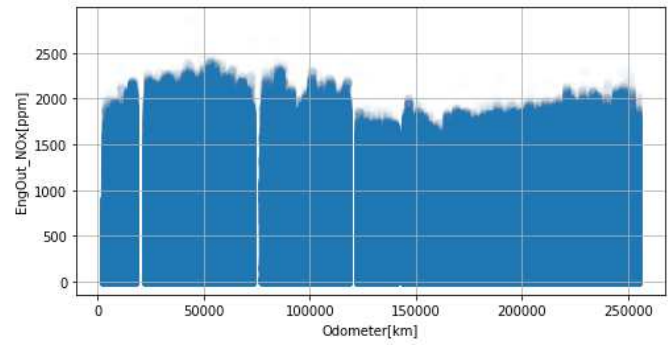

(b) After preprocessing

Figure 6 Demo for unmodifiable outliers preprocessing

\subsubsection{Derived Parameter Calculation}

\section{- NOx Dry/wet correction}

Due to the concentration was measured on a dry basis for the on-board NOx sensor, the measured concentration shall be converted to a wet basis according to the following Equations (1-

5):

$$
\begin{gathered}
c_{N O x(w e t)}=c_{N O x(d r y)} * k_{w} \\
k_{w}=\left(1-\frac{1.2442 * H_{a}+111.19 * \omega_{A L F} * q_{m f, i} / q_{m a d, i}}{773.4+1.2442 * H_{a}+q_{m f, i} / q_{m a d, i} * k_{f, w} * 1000}\right) * 1.008 \\
k_{f, w}=0.055594 * w_{A L F}+0.0080021 * w_{D E L}+0.0070046 * w_{E P S} \\
H_{a}=\frac{6.220 * R_{a} * P_{a}}{P_{B}-P_{a} * R_{a} * 100} \\
P_{a}=\left(4.856884+0.2660089 * T_{a}+0.01688919 * T_{a}^{2}-7.477123 * 10^{-5} * T_{a}^{3}\right. \\
\left.+8.10525 * 10^{-6} * T_{a}^{4}-3.115221 * 10^{-8} * T_{a}^{5}\right) *(101.32 / 760)
\end{gathered}
$$

where:

$c_{N O x(w e t)}$ is the wet concentration in ppm; 
$c_{N O x(d r y)}$ is the dry concentration in ppm (NOx sensor observed value );

$k_{w}$ is the dry/wet correction factor;

$H_{a}$ is the intake air humidity, g water per kg dry air;

$q_{m f, i}$ is the instantaneous fuel mass flow rate, $\mathrm{kg} / \mathrm{h}$;

$q_{\text {mad }, i}$ is the instantaneous dry intake air mass flow rate, $\mathrm{kg} / \mathrm{h}$;

$\omega_{A L F}$ is the hydrogen content of the fuel, percent mass;

$w_{D E L}$ is the nitrogen content of the fuel, percent mass;

$w_{E P S}$ is the oxygen content of the fuel, percent mass;

$T_{a}$ is temperature of the intake air, ${ }^{\circ} \mathrm{C}$;

$R_{a}$ is relative humidity of the intake air,\%;

$P_{a}$ is saturation vapour pressure of the intake air, $\mathrm{kPa}$;

$P_{B}$ is total barometric pressure, $\mathrm{kPa}$.

$$
\begin{gathered}
q_{m N O x, i}=0.001587 * q_{m e w, i} * c_{N O x(\text { wet }), i} \\
q_{m e w, i}=q_{\text {maw }, i}+q_{m f, i}
\end{gathered}
$$

where:

$q_{m N O x, i}$ is the instantaneous NOx mass flow rate, $\mathrm{g} / \mathrm{h}$

$c_{N O x(w e t), i}$ is the instantaneous wet concentration in ppm

$q_{\text {mew }, i}$ is the instantaneous exhaust mass flow rate, $\mathrm{kg} / \mathrm{h}$ 
$q_{\text {maw }, i}$ is the instantaneous intake air mass flow rate, $\mathrm{kg} / \mathrm{h}$

$q_{m f, i}$ is the instantaneous fuel mass flow rate, $\mathrm{kg} / \mathrm{h}$

- Engine Power

The calculation of the engine power shall be according to the following Equations (8-9):

$$
\text { Eng_Power }=\frac{\text { Eng_Speed } * \text { Eng_Tor } / 100 * \text { Torque_refer }}{9550}
$$

$$
\text { Eng_Tor }=\text { Tor }_{\text {Act,Eng }}-\text { Tor }_{\text {Fric }}
$$

Where:

$$
T o r_{\text {Act Eng }} \text { is actual engine percent torque, } \%
$$

Tor $_{\text {Fric }}$ is friction percent torque, $\%$

Torque_refer is 3000 N.m

\section{- Instantaneous NOx brake specific emission}

The calculation of the instantaneous NOx brake specific emission $(\mathrm{g} / \mathrm{kW} . \mathrm{h})$ shall be according to the following Equation (10):

$$
\text { BSNOx }_{i}=\frac{q_{m N O x, i}}{\text { Eng_Power }}
$$

\subsubsection{Feature selection}

In this paper, we mainly focused on engine out NOx. However, the vehicle location parameters, aftertreatment system parameters, and some indicative parameters (e.g. fuel level) didn’t directly affect the engine out NOx emission. These features can be dropped during data preprocessing.

Moreover, the derived parameters obtained in section 3.1.2 can be incorporated into the dataset for engine out NOx analysis.

After the above data preprocessing, we can get the "Clean Dataset", and the parameters of "Clean Dataset" were shown in Table 3.

Table3 Parameters in Clean Dataset 


\begin{tabular}{|c|c|c|c|c|}
\hline & Parameter & Unit & Source & Label \\
\hline \multirow{3}{*}{ Ambient } & Ambient Temperature & ${ }^{\circ} \mathrm{C}$ & Sensor & "T_Air" \\
\hline & Ambient Relative Humidity & $\%$ & Sensor & "RH_Air" \\
\hline & Atmospheric Pressure & $\mathrm{kPa}$ & EECU & "P_Air" \\
\hline \multirow{3}{*}{ Vehicle } & Vehicle Speed & $\mathrm{km} / \mathrm{h}$ & VECU & "Veh_Speed" \\
\hline & Odometer & $\mathrm{km}$ & VECU & "Odometer" \\
\hline & Gear & 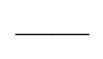 & VECU & "Gear" \\
\hline \multirow{14}{*}{ Engine } & Engine Speed & rpm & EECU & "Eng_Speed" \\
\hline & Actual Engine Percent Torque & $\%$ & EECU & "Act_Eng_Tor" \\
\hline & Nominal Friction Percent Torque & $\%$ & EECU & "Fric_Tor" \\
\hline & Throttle Opening & $\%$ & EECU & "Throttle_Opening" \\
\hline & Rail Pressure & $\mathrm{hPa}$ & EECU & "P_Rail" \\
\hline & Injection Timing & ${ }^{\circ} \mathrm{CA}$ & EECU & "Inj_Timing " \\
\hline & Fuel Consumption Rate & $\mathrm{kg} / \mathrm{h}$ & EECU & "Fuel_mRate" \\
\hline & A ccumulative Ful Concumntion & I & FECU & "Acr Fuel Conc" \\
\hline & Intercooler Outlet Temperature & ${ }^{\circ} \mathrm{C}$ & EECU & "T_AirC_O" \\
\hline & Intercooler Outlet Pressure & $\mathrm{kPa}$ & EECU & "P_AirC_O" \\
\hline & Intake Mass Flow & $\mathrm{kg} / \mathrm{h}$ & EECU & "Int_MassFlow" \\
\hline & Intake Valve Opening & $\%$ & EECU & "Int_Valve_Opening" \\
\hline & Coolant Temperature & ${ }^{\circ} \mathrm{C}$ & EECU & "T_Coolant" \\
\hline & Oil Temperature & ${ }^{\circ} \mathrm{C}$ & EECU & "T_Oil" \\
\hline
\end{tabular}




\begin{tabular}{|c|c|c|c|c|}
\hline & Oil Pressure & $\mathrm{kPa}$ & EECU & "P_Oil" \\
\hline & Engine Out NOx(wet) & ppm & Calculation & "EngOut_NOx_wet" \\
\hline & Engine Out Mass Flow & $\mathrm{g} / \mathrm{h}$ & Calculation & "EngOut_NOx_MF" \\
\hline Deprived & Net Percent Torque & $\%$ & Calculation & "Eng_Tor" \\
\hline \multirow[t]{3}{*}{ Parameters } & Engine Power & $\mathrm{kW}$ & Calculation & "Eng_Power" \\
\hline & Brake Specific Engine Out NOx & $\mathrm{g} / \mathrm{kW} \cdot \mathrm{h}$ & Calculation & "BSEngOut_NOx" \\
\hline & Absolute Humidity & $\mathrm{g} / \mathrm{kg}$ & Calculation & "Ha" \\
\hline
\end{tabular}

\section{Results and Discussion}

Based on the data getting from $254,622 \mathrm{~km}$ durability test of the tested vehicle, we carried out the research for engine out NOx emission deterioration, at the same time, completed the NOx correction for ambient air temperature and humidity.

\subsection{Results}

In this paper, the "Clean Dataset", "Basic Dataset" and "Analysis Dataset" were obtained according to the methods shown in Section 3.1, the datasets scale, specific methods and constraint conditions were shown in the Table 4.

The "Raw Dateset" in Table 4 was the data of 254,622 km durability test. The "Clean Dataset" was got by data preprocessing described in Section 3.2 in this paper.

Table 4 Scale of Datasets and Method/Constraint Condition

\begin{tabular}{ccccc}
\hline \multicolumn{2}{c}{ Input Dataset } & & & Method / \\
Name & Rows & Columns & Constraint Condition & Output Dataset \\
\cline { 1 - 2 } Raw Dataset & $11,250,364$ & 37 & Data Preprocessing & Clean Dataset \\
Clean Dataset & $9,962,537$ & 27 & Getting Eng_Speed max Weight Bin/ & Dataset_A
\end{tabular}


Eng_Speed $=1200 \pm 2[\mathrm{rpm}]$

Getting Eng_Tor max Weight Bin /

\begin{tabular}{|c|c|c|c|c|}
\hline \multirow[t]{2}{*}{ Dataset_A } & 130,135 & 27 & & \multirow[t]{2}{*}{ Basic Dataset } \\
\hline & \multicolumn{3}{|r|}{ Eng_Tor $=50 \pm 1[\%]$} & \\
\hline & & & Intake Air Parameter Filtering/ & \\
\hline \multirow[t]{3}{*}{ Basic Dataset } & 25,417 & 27 & & Dataset_B \\
\hline & & & Int_MassFlow IQR & \\
\hline & & & Fuel injection Parameters Filtering/ & \\
\hline \multirow[t]{3}{*}{ Dataset_B } & 23,825 & 27 & & Dataset_C \\
\hline & & & Fuel_Rate IQR & \\
\hline & & & Fuel injection Parameters Filtering/ & \\
\hline \multirow[t]{3}{*}{ Dataset_C } & 21,348 & 27 & & Dataset_D \\
\hline & & & Injection Timing IQR & \\
\hline & & & Ambient Parameter Joint Filtering/ & \\
\hline \multirow[t]{2}{*}{ Dataset_D } & 19,733 & 27 & & Analysis Dataset \\
\hline & & & EngOut_NOx_MF vs Ha (linear) & \\
\hline Analysis Dataset & 12,144 & 27 & $\mathrm{Ha}=15 \pm 0.5[\mathrm{~g} / \mathrm{kg}]$ & Dataset_E \\
\hline
\end{tabular}

IQR: Interquartile range

\subsubsection{Basic Dataset acquisition}

Figure 7(a) shows the frequency distribution (bins=30) of engine speed on "Clean Dataset". Within its maximum weight range $[1185,1259] \mathbf{~ r p m}$, we had taken $1200 \pm 2 \mathrm{rpm}$ as the constraint condition to get a new dataset named "Dataset_A", where, \pm 2 is the tolerance range of engine speed, so as to avoid the scale of the dataset being too small, similarly hereinafter.

Figure 7(b) shows the frequency distribution (bins=30) of net percent torque on "Dataset_A",

196 and within its maximum weight range $[\mathbf{4 8}, \mathbf{5 1 ]} \%$, we had taken $50 \pm 1 \%$ as the constraint condition, then we got the "Basic Dataset" for the following research. 


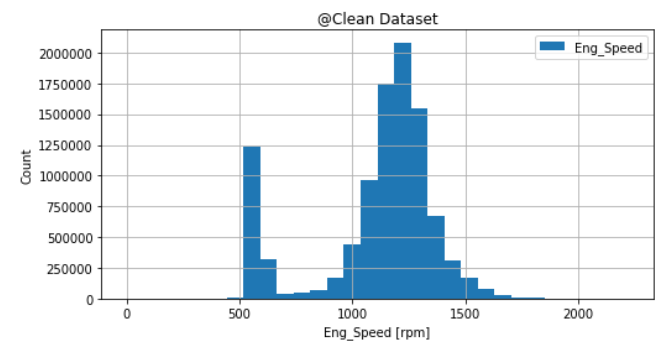

(a)

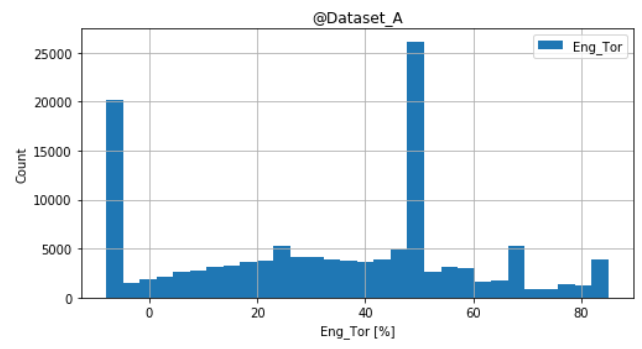

(b)

Figure7 (a) Eng_Speed distribution@Clean Dataset; (b) Eng_Tor distribution @ Dataset_A

\subsubsection{Basic Dataset preprocessing}

The analysis of the deterioration of engine out NOx shall be carried out on a certain steady working condition (for in-use vehicles) or established cycles (for engine bench, whether transient or steady). Therefore, for the tested vehicle, before the engine out NOx deterioration research, we should ensure the dataset used for the research was a "steady" one.

On the "Basic Dataset", although the engine speed and engine torque were almost the same, the dataset contained many transition operating points, some outliers, and shot noise, etc. Therefore, in order to obtain the dataset of a certain steady working condition as accurate as possible, it is necessary to filter the "Basic Dataset" to eliminate the influence of transition working conditions and noise points on the final results.

For a given diesel engine and a given working condition, engine out NOx is mainly affected by intake air parameters and fuel injection parameters. The intake air parameters are main affected by ambient air parameters. So, we could use these parameters to filter the "Basic Dataset", then we would get the "Analysis Dataset".

\section{- Intake air parameter filtering}

Figure 8(a) shows the intake air mass flow versus odometer on "Basic Dataset". As it can be seen, there were many outliers and shot noise points, which were basically generated by transition 
working conditions.

Figure 8(b) shows the frequency distribution of the intake air mass flow. As it can be seen, the

218 intake air mass flow distribution was relatively concentrated, so interquartile range (IQR) can be used for filtering. If the value was less than the minimum or greater than the maximum showed in

Figure 9, it would be dropped.

Figure 8(c) shows the box-plot of the intake air mass flow (the minimum is $835.0 \mathrm{~kg} / \mathrm{h}$, the maximum is $1071.0 \mathrm{~kg} / \mathrm{h}$ )

Figure 8(d) shows the result of the intake air mass flow that had been filtered by IQR. the filtering of intake air mass flow, we got "Dataset_B".

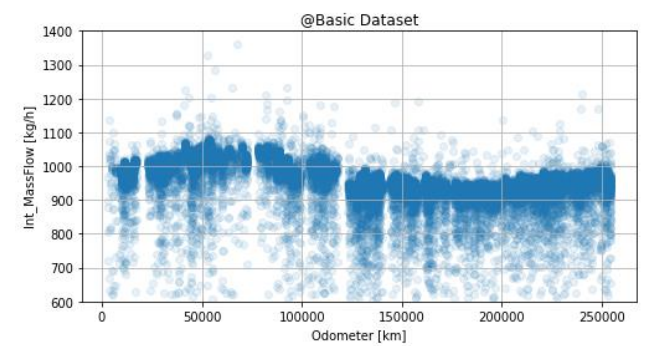

(a)

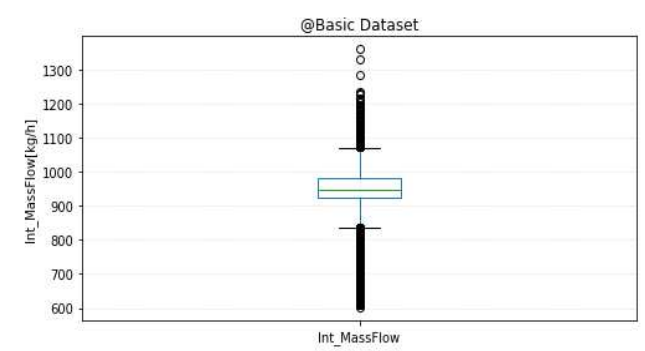

(c)

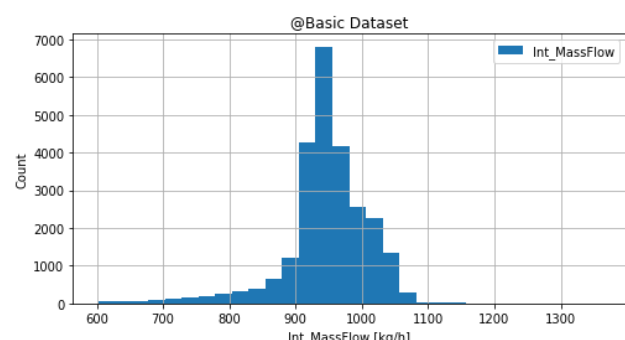

(b)

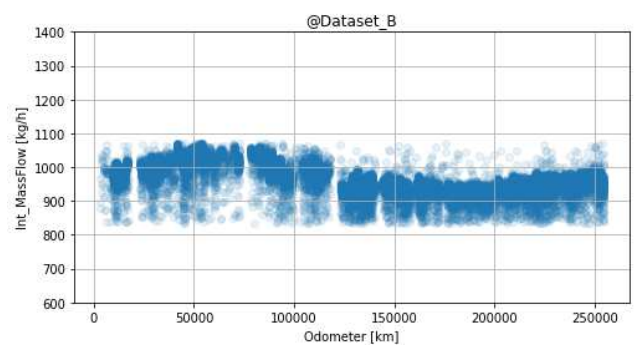

(d)

Figure 8 Intake air parameter filtering. (a) Int_MassFlow vs odometer@ @ Basic Dataset; (b) Int_MassFlow frequency distribution@Basic Dataset; (c) Int_MassFlow box-plot@ @ Basic Dataset; (d) Int_MassFlow vs odometer@ Dataset_B; 


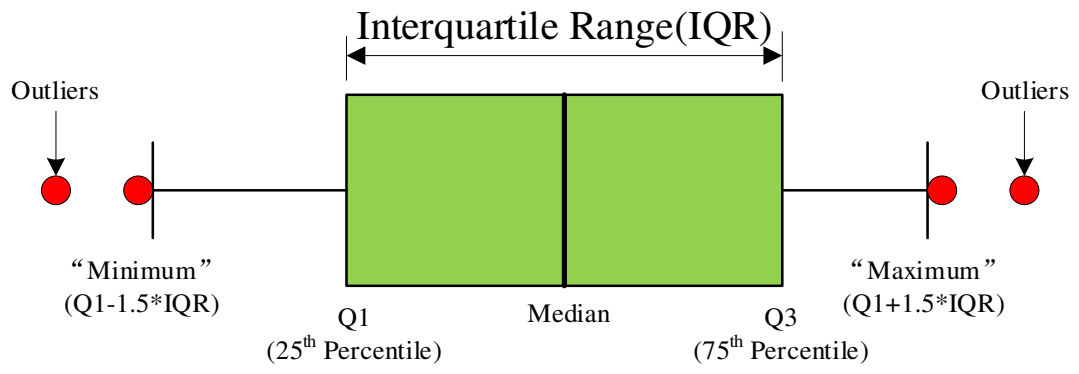

Figure 9 IQR (box-plot) filtering schematic plot

- Fuel injection parameters filtering

Figure 10(a) shows the fuel consumption rate versus odometer on "Dataset_B". Figure 10(b)

Figure 10(c) shows the injection timing versus odometer on "Dataset_C". Figure 10(d) shows the box-plot of injection timing (the minimum is $5.83 \mathrm{BTDC}^{\circ} \mathrm{CA}$, the maximum is $5.99 \mathrm{BTDC}{ }^{\circ} \mathrm{CA}$ ). We got "Dataset_D” after filtering injection timing by IQR.

Figure 10(e) shows the fuel consumption rate versus injection timing on "Dataset_B". As it can be seen, for a given operation condition of the tested vehicle, the larger the injection timing is, the higher the fuel consumption is. As we know, the larger the injection timing is, the higher the combustion temperature is, the higher combustion temperature would lead to higher engine out NOx emission. So, we had taken both fuel consumption rate and injection timing as the constraint conditions to ensure the consistency of the injection parameters. 


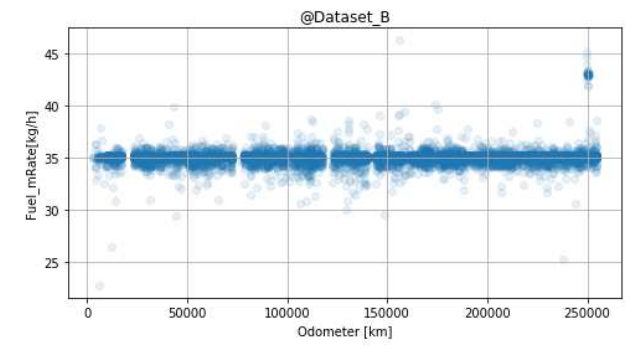

(a)

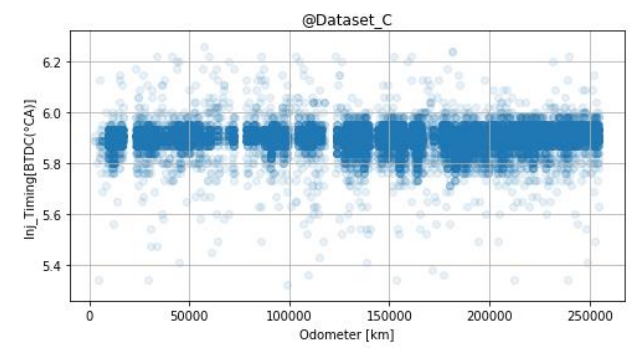

(c)

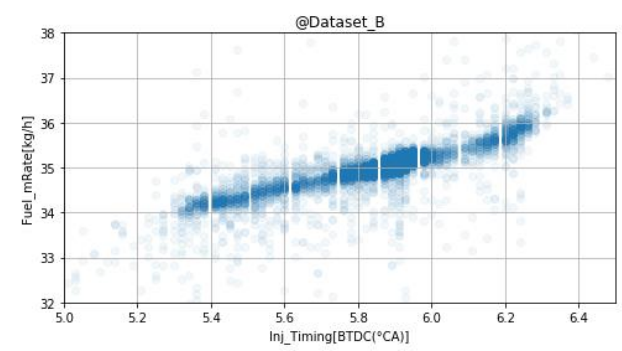

(e)

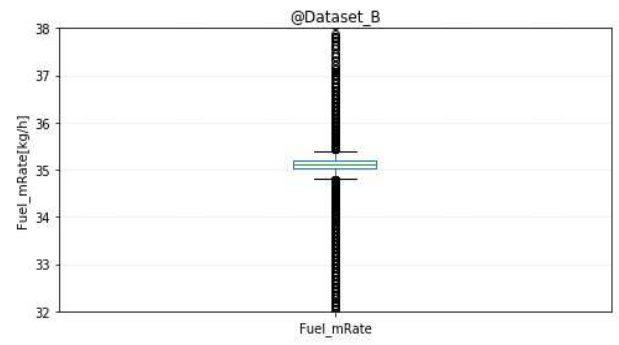

(b)

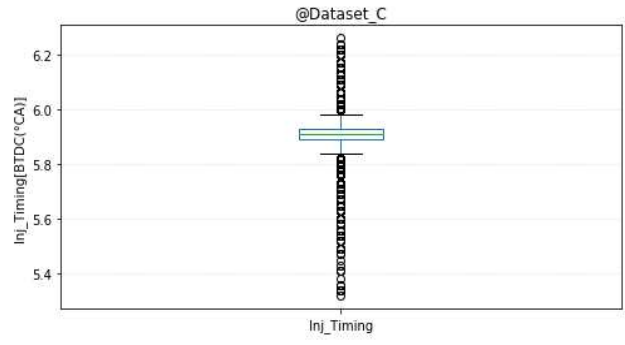

(d)

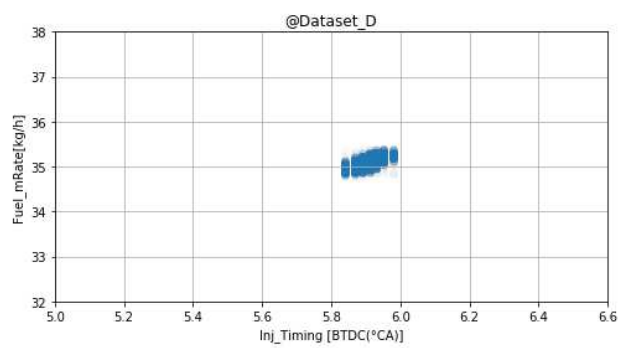

(f)

Figure 10 Fuel injection parameters filtering (a) Fuel_mRate vs odometer @ Dataset_B; (b) Fuel_mRate box-plot@Dataset_B; (c) Inj_Timing vs odometer@Dataset_C; (d) Inj_Timing boxplot@Dataset_C; (e) Inj_Timing vs Fuel_mRate@ Dataset_B; (f) Inj_Timing vs Fuel_mRate@ Dataset_D;

\section{- Ambient parameters and engine out NOx mass flow joint filtering}

Figure 11(a) shows the frequency distribution of absolute humidity (Ha) on "Dataset_D". The distribution of Ha is relatively dispersed. Therefore, IQR filtering method can no longer be suitable for filtering ambient parameters.

Figure 11(b) shows Ha distribution in different seasons on "Dataset_D". As it can be seen, Ha 


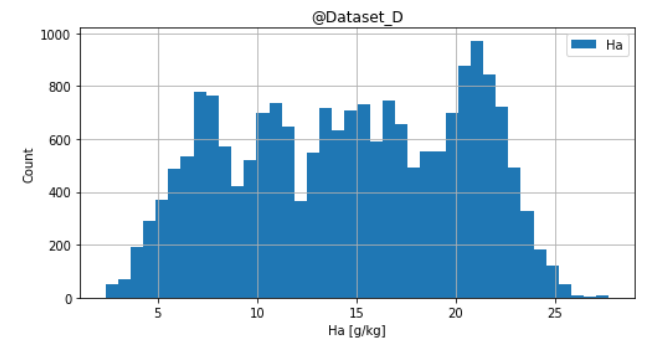

(a)

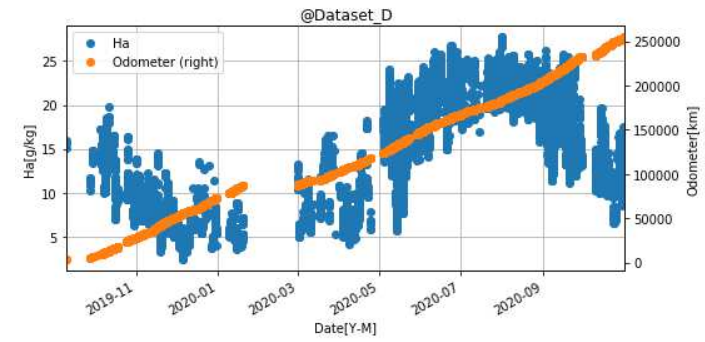

(b)

Figure 11 (a) Ha distribution@ Dataset_D; (b) Ha \& odometer vs Date @ Dataset_D

After the intake air parameter and fuel injection parameters filtering, absolute humidity (Ha), was the most related ambient parameter to engine out NOx mass flow. The Pearson correlation coefficient between engine out NOx mass flow and Ha changed from -0.359 (on "Clean Dataset") to $\mathbf{- 0 . 5 8 7}$ (on "Dataset_D").

As it was shown in Figure 12(a), on the whole, there was a good linear relationship (fitting function: $\left.y=-16.444^{*} x+1562.7\right)$ between engine out NOx mass flow and Ha. But, there were still many shot noise points which may lead to a lower Pearson correlation coefficient and relatively big error for the final results or conclusions. Therefore, before the quantitative analysis of the impact of ambient factors on engine out NOx emission, these shot noise points should be filtered out. The specific filtering steps were as follows:

Step 1: Fitting a function $\mathrm{f}$ (Equation 11), then getting $\mathrm{k}$ and $\mathrm{b}$;

$$
\text { EngOut_NOx_MF }=f(H a)=k * H a+b
$$

Step2: Calculating the instantaneous engine out NOx mass flow at the observed Ha by using $\mathrm{k}$ and b in step 1 (Equation 12)

$$
\text { Eng_Out_NOx_Cal }{ }_{i}=k^{*} H a_{i}+b
$$




$$
\text { Ratio }_{i}=\text { EngOut }_{-} \mathrm{NOx}_{-} \mathrm{MF}_{i} / \mathrm{Eng}_{-} \mathrm{Out} \mathrm{N}_{-} \mathrm{NOx_{- }} \mathrm{Cal}_{i}
$$

Step4: Setting a range $[\mathbf{0 . 9 5}, \mathbf{1 . 0 5}]$ for ratio, filtering by the ratio, then getting a new dataset.

Step5: Repeating step1-4 until the difference of two successive iterations $\mathrm{k}$ is less than $1 \%$.

Figure 12(b) shows the result of the Ha and engine out NOx mass flow joint filtering on "Dataset_D". The fitting function is $y=-16.963^{*} x+1588.7$, then we got "Analysis Dataset".

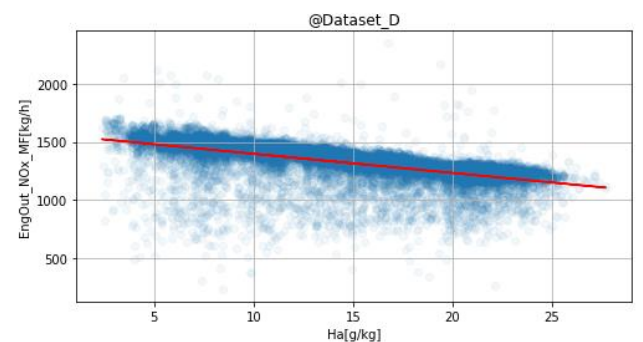

(a)

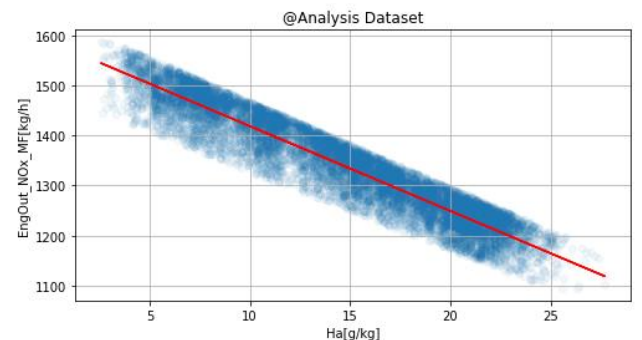

(b)

Figure 12 Ambient parameters and engine out NOx mass flow joint filtering; (a) Ha vs EngOut_NOx_MF@Dataset_D; (b) Ha vs EngOut_NOx_MF@ Analysis Dataset;

Figure 13(a) and Figure 13(b) show engine power vs odometer on "Basic Dataset" and “Analysis Dataset" respectively, as it can be seen, after the abovementioned filtering, the engine power on "Analysis Dataset" was all almost the same in 254,622 km durability test. So "Analysis Dataset" could be considered as a "steady" dataset.

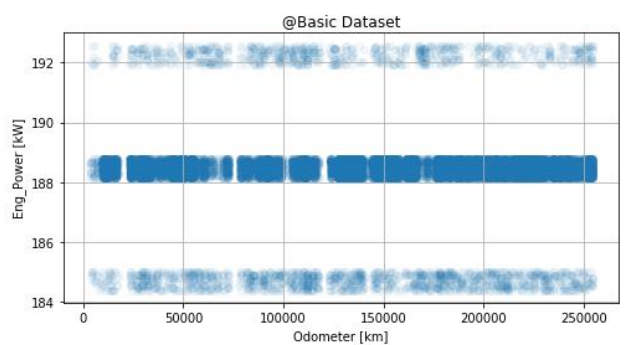

(a)

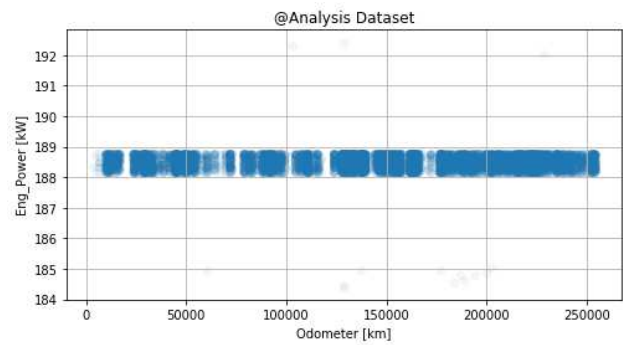

(b)

Figure 13 (a) Eng_Power vs Odometer@ Basic Dataset; (b) Eng_Power vs Odometer@ Analysis 
Dataset;

\subsection{Analysis of engine out NOx emission deterioration}

On "Analysis Dataset", the Pearson correlation coefficient between engine out NOx mass flow

and Ha was -0.947 (Table 5), without considering the deterioration, engine out NOx mass flow was most related to $\mathrm{Ha}$.

Table 5 Pearson correlation coefficient for EngOut_NOx_MF@Analysis Dataset

\begin{tabular}{llllll}
\hline EngOut_NOx_MF & 1.000 & Fuel_mRate & 0.047 & T_Coolant & -0.061 \\
\hline BSEO_NOx & 1.000 & Eng_Tor & 0.018 & RH_Air & -0.082 \\
EngOut_NOx_wet & 0.898 & Act_Eng_Tor & 0.018 & T_Oil & -0.350 \\
Int_MassFlow & 0.859 & Eng_Power & 0.016 & Odometer & -0.534 \\
P_AirC_O & 0.777 & P_Rail & 0.009 & Acc_Fuel_Cons & -0.541 \\
P_Air & 0.569 & Eng_Speed & 0.007 & T_AirC_O & -0.859 \\
P_Oil & 0.080 & Int_Valve_Opening & -0.021 & T_Air & -0.863 \\
Throttle_Opening & 0.064 & Gear & -0.045 & Ha & $\mathbf{- 0 . 9 4 7}$ \\
Inj_Timing & 0.060 & Veh_Speed & -0.045 & Fric_Tor & - \\
\hline
\end{tabular}

Therefore, further taking $\mathrm{Ha}=15 \pm 0.5 \mathrm{~g} / \mathrm{kg}$ which could cover a wider range of mileage or seasons (Figure 11(b)) as a constraint condition, we can got a new dataset named "Dataset_E" on which we could analyse the deterioration of engine out NOx emission.

Figure 14(a) shows the deterioration of engine out NOx mass flow $(\mathrm{g} / \mathrm{h})$ and Figure 14(b) shows the deterioration of the engine out NOx brake specific emission (g/kW.h) on "Dataset_E". 


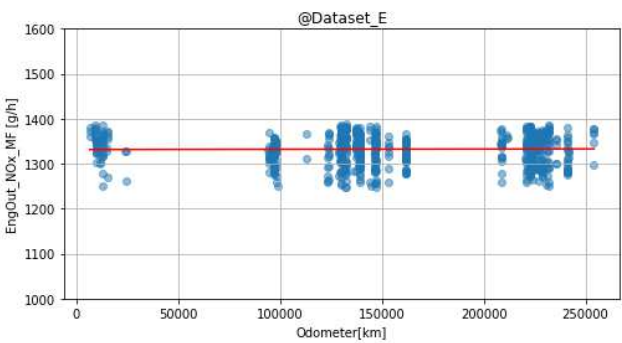

(a)

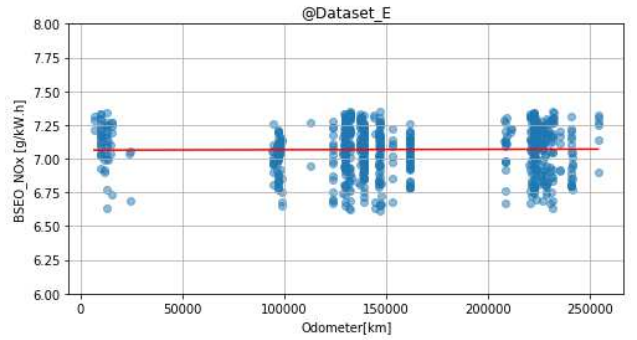

(b)

\begin{tabular}{|c|c|c|c|}
\hline & & \multirow{2}{*}{$\begin{array}{c}\text { Eng_Out NOx } \\
{[\mathrm{g} / \mathrm{h}]}\end{array}$} & \multirow{2}{*}{$\begin{array}{c}\text { Eng_Out NOx } \\
\quad[\mathrm{g} / \mathrm{kW} . \mathrm{h}]\end{array}$} \\
\hline & & & \\
\hline Deterioration & $\mathrm{k}$ & $6.102 \mathrm{E}-06$ & $2.770 \mathrm{E}-08$ \\
\hline \multirow[t]{2}{*}{ Equation } & $\mathrm{b}$ & 1331.3 & 7.063 \\
\hline & 0 & 1331.3 & 7.063 \\
\hline \multirow[t]{2}{*}{ Odometer [km] } & 254,622 & 1332.9 & 7.070 \\
\hline & 700,000 & 1335.6 & 7.083 \\
\hline \multicolumn{2}{|c|}{ Deterioration Factor (DF) @ 254,622km } & 1.001 & 1.001 \\
\hline Deterioration Facto & $0,000 \mathrm{~km}$ & 1.003 & 1.003 \\
\hline
\end{tabular}

Figure 14 (a) EngOut_NOx_MF vs Odometer @ Dataset_E; (b) BSEngOut_NOx vs Odometer@

Dataset_E;

The deterioration function and deterioration factor were shown in Table 6. As it can be seen, within $254,622 \mathrm{~km}$, for the maximum weight working condition (including ambient condition) of the tested vehicle, the deterioration factors of engine out NOx mass flow and engine out NOx brake specific emission were 1.001 and 1.001 , respectively

Table 6 The deterioration information for engine out NOx@ Dataset_E 


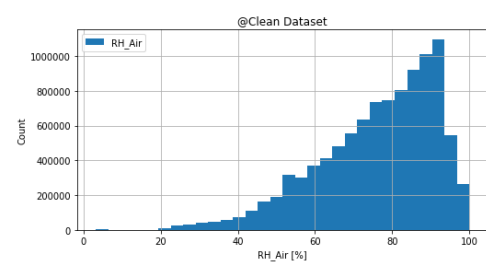

(a)

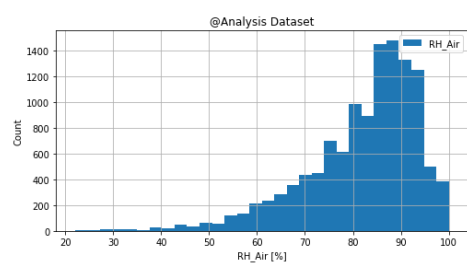

(b)

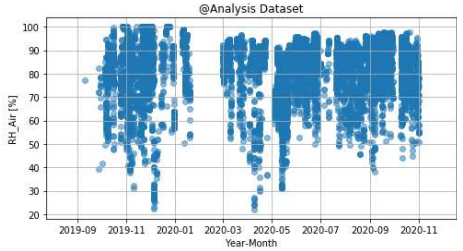

(c)

Figure 15 (a) RH_Air distribution@Clean Dataset; (b) RH_Air distribution@Analysis Dataset; (c)

RH_Air vs Date@Analysis Dataset 


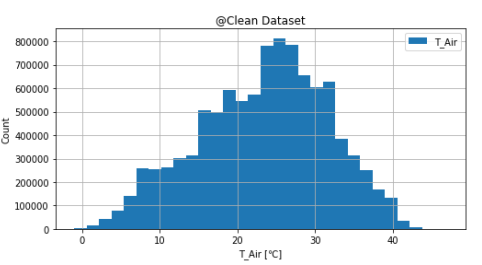

(a)

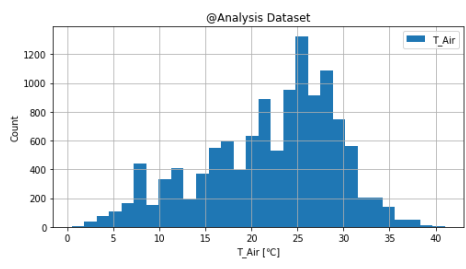

(b)

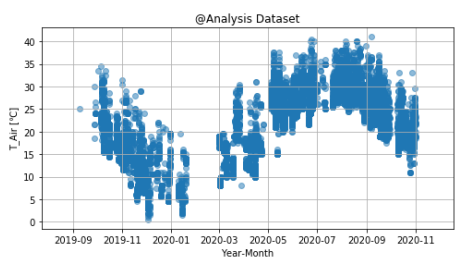

(c)

Figure16 (a) T_Air distribution@Clean Dataset; (b) T_Air distribution @aAnalysis Dataset; (c) T_Airvs Date @ Analysis Dataset

Figure 17(a) and Figure 17(b) showed the distribution of Ha on "Clean Dataset" and "Analysis Dataset" respectively. As it can be seen, the trend of Ha changing with the season was almost the same as that of the ambient temperature (Figure 16(c), Figure 17(c)).

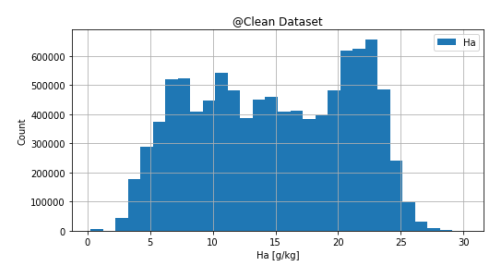

(a)

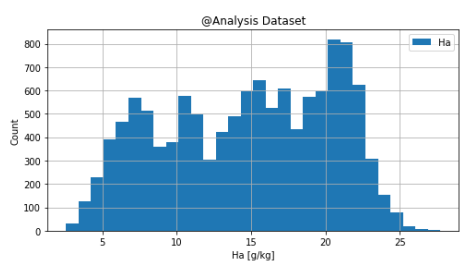

(b)

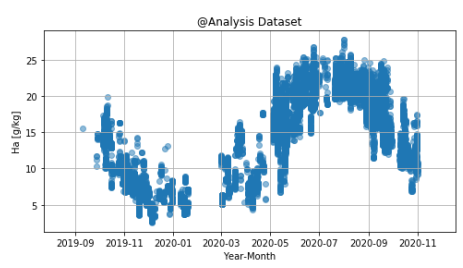

(c)

Figure17 (a)Ha distribution@Clean Dataset; (b) Ha distribution@Analysis Dataset; (c) Ha vs Date@ Analysis Dataset

Figure 18 shows the relationship between Ha and ambient temperature/relative humidity. The functional relationship can be described by Equation 14.

$$
H a=(0.0372 * R H a+0.5212) * e^{0.063^{*} T a}
$$

Where: $\mathrm{RHa}$ is relative humidity, $\%$; Ta is ambient temperature, ${ }^{\circ} \mathrm{C}$.

If the relative humidity remained the same or varied in a small range, Ha had an exponential relationship with the ambient temperature.

When the ambient temperature was at a low level, the variety of relative humidity has little effect on $\mathrm{Ha}$, in other words, the lower ambient temperature would directly lead to lower Ha in 
winter.

The larger the Ha is, the larger the specific heat capacity of the intake air is. Larger Ha would

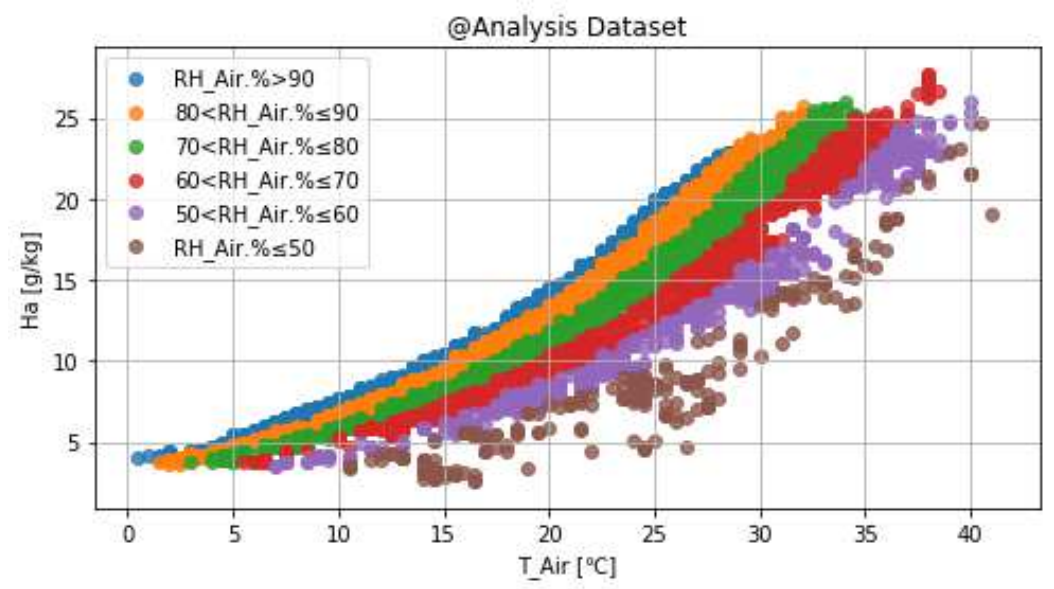

Figure 18 The relationship between Ha and ambient temperature/relative humidity

\subsubsection{The effect of ambient factors to engine out NOx emission}

In this section, we mainly discuss the effect of ambient factors (ambient temperature and absolute humidity(Ha)) on engine out NOx concentration ( $\mathrm{ppm}$ ) and engine out NOx mass flow $(\mathrm{g} / \mathrm{h})$.

- Ambient temperature vs engine out NOx (ppm)

Figure 19(a) shows ambient temperature vs engine out NOx concentration (ppm, wet basis) on "Analysis Dataset"; Figure 19(b) shows the average value of engine out NOx concentration (ppm, wet basis) at different ambient temperature $\left(\right.$ step $\left.=1{ }^{\circ} \mathrm{C}\right)$. As it can be seen, when the ambient temperature is within the range of $20 \sim 30^{\circ} \mathrm{C}$, there is a negative linear relationship between ambient temperature and engine out NOx concentration $\left(R^{2}=0.927\right)$. But, when the ambient temperature is lower than $20^{\circ} \mathrm{C}$ or higher than $30^{\circ} \mathrm{C}$, the change of ambient temperature has little effect on engine out NOx concentration (within 20ppm). 


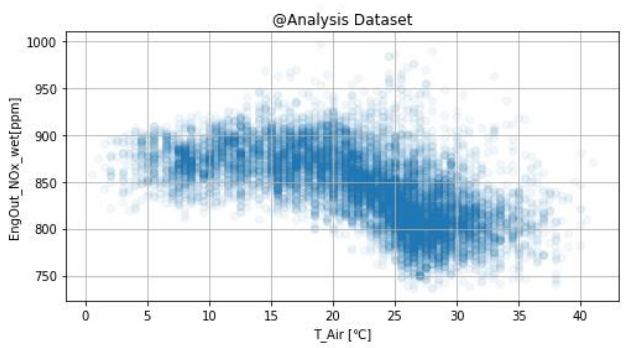

(a)

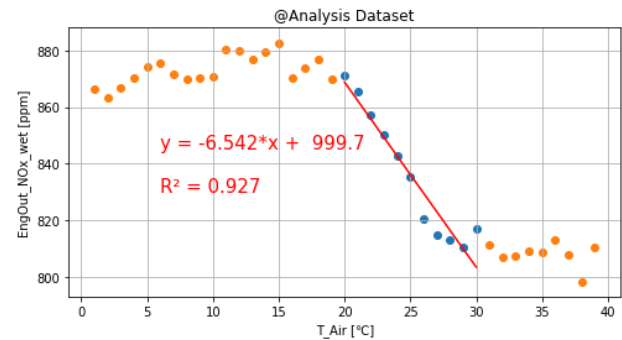

(b)

Figure 19 (a) T_Air vs EngOut_NOx_wet @ Analysis Dataset; (b) T_Air vs EngOut_NOx_wet (mean)@ Analysis Dataset;

\section{- Ha vs engine out NOx (ppm)}

Figure 20(a) shows Ha vs engine out NOx concentration (ppm, wet basis) on "Analysis Dataset"; Figure 20(b) shows the average value of engine out NOx concentration (ppm, wet basis) at different $\mathrm{Ha}$ ( $\mathrm{step}=1 \mathrm{~g} / \mathrm{kg}$ ). As it can be seen, when Ha is lower than $12 \mathrm{~g} / \mathrm{kg}$, the change of $\mathrm{Ha}$ had little effect on engine out NOx concentration (within 20ppm), otherwise, engine out NOx concentration had a good negative linear relationship with $\mathrm{Ha}\left(\mathrm{R}^{2}=0.978\right)$.

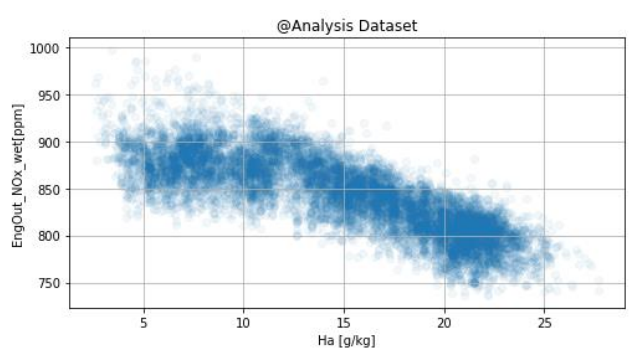

(a)

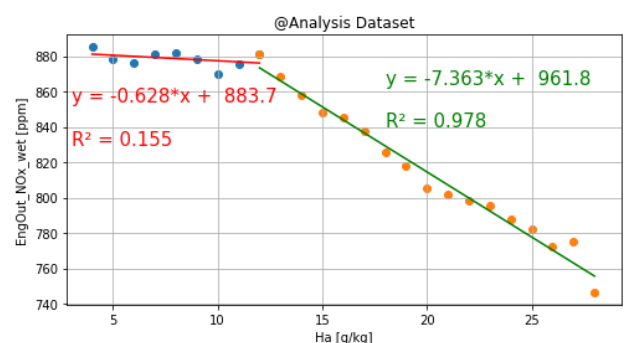

(b)

Figure 20 (a) T_Air vs EngOut_NOx_wet @ Analysis Dataset; (b) T_Air vs EngOut_NOx_wet (mean)@ Analysis Dataset;

\section{- Ambient temperature vs intake air mass flow}

According to Equation 6 and Equation 7, the engine out NOx mass flow is affected by the exhaust mass flow and engine out NOx concentration (wet basis, ppm). On "Analysis Dataset", the 
exhaust mass flow is mainly affected by the intake air mass flow because the fuel consumption rate is almost the same. nRT, the intake air mass flow will be affected by intercooler outlet temperature.

Figure 21(a) shows intercooler outlet temperature versus ambient temperature; Figure 21(b) shows intake air mass flow versus ambient temperature; Figure 21(c) shows ambient temperature versus the average value of intake air mass flow at different ambient temperature (step $=1^{\circ} \mathrm{C}$ ). As it can be seen, the intake air mass flow had a good negative linear relationship with ambient temperature $\left(\mathrm{R}^{2}=0.993\right)$.

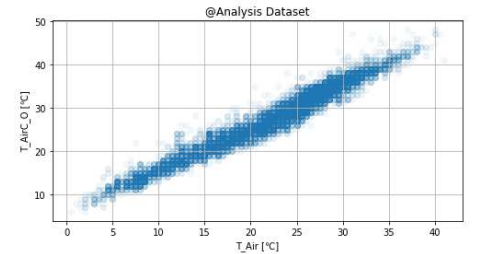

(a)

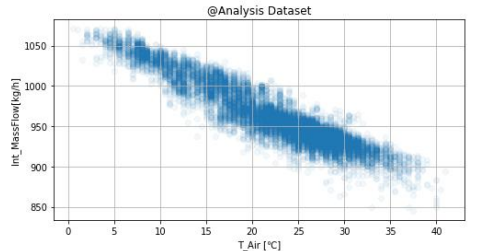

(b)

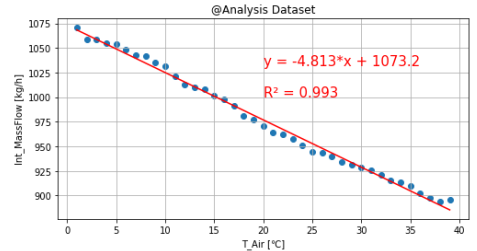

(c)

Figure 21 (a) T_Air vs T_AirC_O @ Analysis Dataset; (b) T_Air vs Int_MassFlow @ Analysis

Dataset; (c) T_Airvs Int_MassFlow (mean) @ Analysis Dataset

- Ha vs intake air mass flow

Figure 22(a) shows intake air mass flow versus Ha on "Analysis Dataset"; Figure 22(b) shows the average value of intake air mass flow at different $\mathrm{Ha}(\mathrm{step}=1 \mathrm{~g} / \mathrm{kg}$ ). As it can be seen, Ha lower $\mathrm{g} / \mathrm{kg}(\boldsymbol{k}=\mathbf{- 3 . 9 4 3 )}$. 


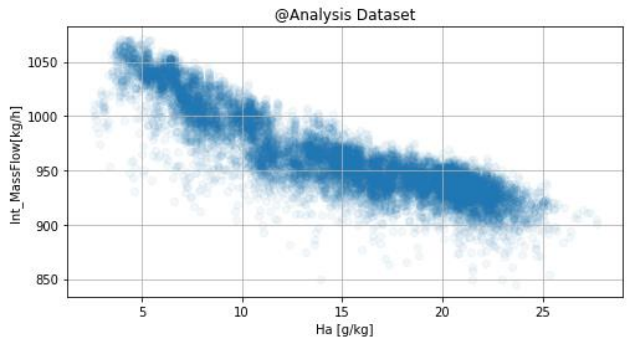

(a)

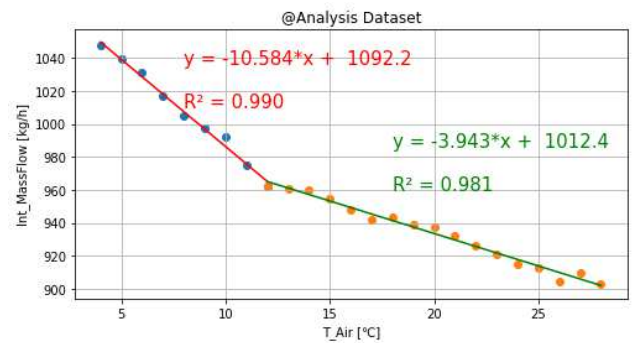

(b)

Figure 22 (a) Ha vs Int_MassFlow @ Analysis Dataset; (b) Ha vs Int_MassFlow (mean) @ Analysis

Dataset.

\section{- Ha vs engine out NOx (g/h)}

Figure 23(a) shows Ha vs engine out NOx mass flow (g/h) on Analysis Dataset; Figure 23(b) shows the average value of engine out NOx mass flow $(\mathrm{g} / \mathrm{h})$ at different $\mathrm{Ha}(\mathrm{step}=1 \mathrm{~g} / \mathrm{kg}$ ). Engine out NOx mass flow had a good negative linear relationship with $\mathrm{Ha}\left(\mathrm{R}^{2}=0.997\right)$.

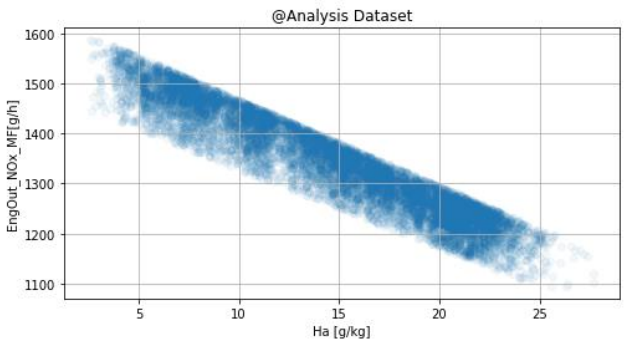

(a)

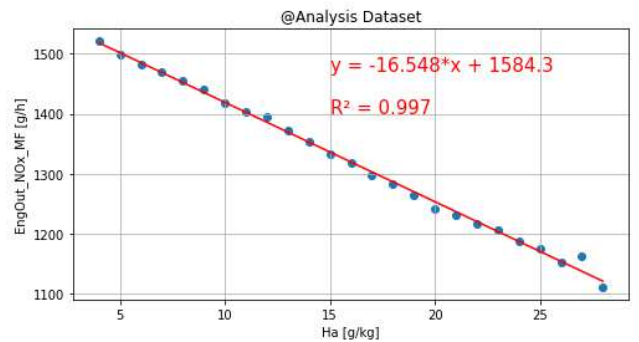

(b)

Figure 23 (a) Ha vs EngOut_NOx_MF@ Analysis Dataset; (b) Ha vs EngOut_NOx_MF (mean) @ Analysis Dataset;

To sum up, for a given steady working condition, whether ambient temperature or Ha, they had different effect on engine out NOx concentration (ppm) at different sections; the exhaust mass flow rate was mainly affected by the ambient temperature; engine out NOx mass flow $(\mathrm{g} / \mathrm{h})$ was mainly affected by Ha. So, we can take the engine out NOx mass flow $(\mathrm{g} / \mathrm{h})$ as the correction target, Ha as the independent variable to study a formula for NOx correction for ambient air temperature and 
humidity based on on-board sensors.

\subsubsection{NOx correction for temperature and humidity}

According to the results of section 4.3.2 in this paper, based on on-board sensors, we had carried out the NOx correction for ambient temperature and humidity as following steps:

Step 1: NOx Dry-Wet correction (It had been done in data preprocessing).

Step2: Setting Ha $=10.71 \mathrm{~g} / \mathrm{kg}$ as the reference, that is to say $\mathrm{K}_{\mathrm{h}, \mathrm{d}}=1 @ \mathrm{Ha}=10.71 \mathrm{~g} / \mathrm{kg}$.

Step3: Calculating the average value of engine out NOx mass flow @ $\mathrm{Ha}=10.71 \pm 0.5 \mathrm{~g} / \mathrm{kg}$ by

\section{Equation 15.}

$$
\text { EngOut_NOx_MF } F_{\text {Base }}=\left(\sum_{i}^{n} \text { EngOut_NOx } \_M F_{H a_{i}=10.71 \pm 0.5}\right) / n
$$

Step4: Calculating the real correction coefficient $\mathrm{K}_{\mathrm{h}, \mathrm{d} \_}$Real of each observation point by Equation 16.

$$
K_{h, d} \text { Real }_{i}=\text { EngOut }_{-} N O x_{-} M F_{\text {Base }} / \text { EngOut_NOx }{ }_{-} M F_{i}
$$

Step5: Fitting a formula for $\mathrm{K}_{\mathrm{h}, \mathrm{d}}$ (Equation 17), then getting $\mathrm{k}$ and $\mathrm{b}$;

$$
K_{h, d}=f(H a)=k * H a+b
$$

Step6: Using $\mathrm{k}$ and $\mathrm{b}$ obtained in step 5 to correct engine out NOx mass flow.

Figure 24(a) shows Ha versus $\mathrm{K}_{\mathrm{h}, \mathrm{d} \_}$Real on Analysis Dataset; Figure 24(b) shows the average value of $\mathrm{K}_{\mathrm{h},{ }_{-}}$Real at different $\mathrm{Ha}($ step $=1 \mathrm{~g} / \mathrm{kg}$, range $=(5,25))$. $\mathrm{K}_{\mathrm{h}, \mathrm{d} \_}$Real had a good positive linear relationship with $\mathrm{Ha}(\mathrm{y}=0.013306 * \mathrm{x}+0.861, \mathrm{R} 2=0.995)$.

$$
K_{h, d}=0.013306 * H a+0.861
$$




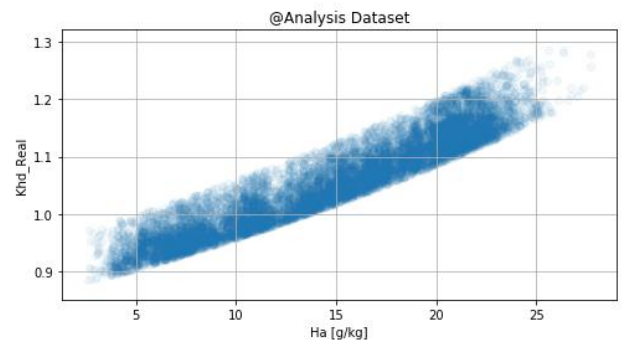

(a)

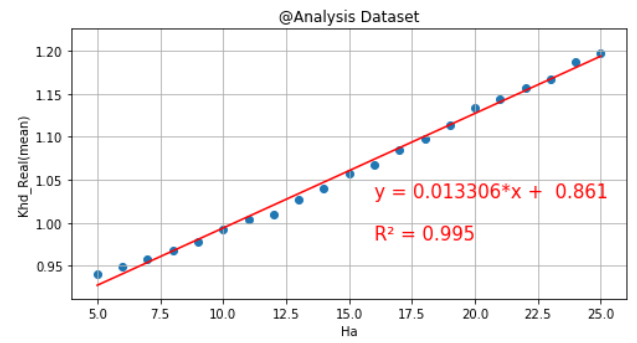

(b)

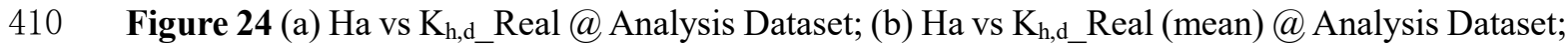

\subsubsection{Verification of NOx correction formula}

For the base point $(\mathrm{Ha}=10.71 \mathrm{~g} / \mathrm{kg}), \mathrm{K}_{\mathrm{h}, \mathrm{d}}=1.004$, The bias was merely $0.4 \%$, So, we may conclude that the accuracy of Equation 18 could be guaranteed for the base point.

Figure 25(a) shows the raw and corrected engine out NOx mass flow versus odometer on "Analysis Dataset". As it can be seen, after ambient temperature and humidity correction, engine out NOx mass flow was on the same level in different seasons, so as the engine out NOx brake specific emission (Figure 25(b)).

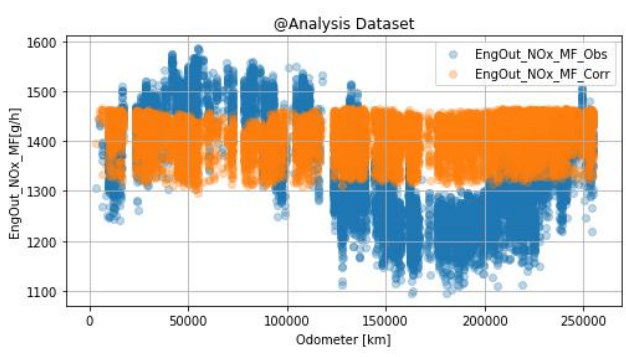

(a)

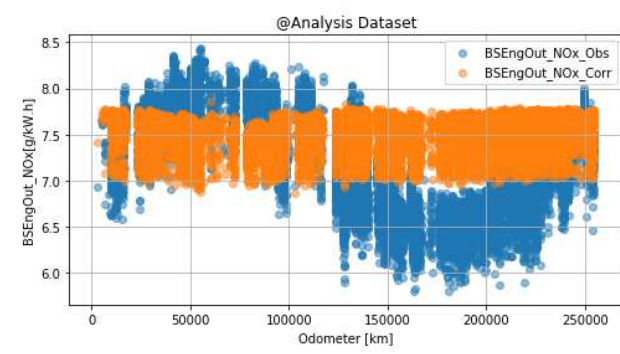

(b)

Figure 25 (a) Odometer vs EngOut_NOx_MF @ Analysis Dataset; (b) Odometer vs BSEngOut_NOx@Analysis Dataset;

Table7 shows the deterioration function (linear) of the corrected engine out NOx mass flow $(\mathrm{g} / \mathrm{h})$ and engine out NOx brake specific emission $(\mathrm{g} / \mathrm{kW} \cdot \mathrm{h})$.

Compared to Table 6, the deterioration factor (@254,622 km) of engine out NOx was 0.004 
higher than that in Table 6, the deterioration factor (@700,000 km) of engine out NOx was 0.011 higher than that in Table 6. Generally, the different between the deterioration factor in Table 6 and Table7 was less than $1.1 \%$.

So, we can conclude that the method used in this paper and the formula (Equation 18) for NOx correction for ambient air temperature and humidity were suitable for on-board sensors and could be used for the deterioration analysis for the in-use vehicle engine out NOx emission.

Table 7 The deterioration information for engine out NOx@ Analysis Dataset

\begin{tabular}{|c|c|c|c|}
\hline & & \multirow{2}{*}{$\begin{array}{c}\text { Eng_Out NOx } \\
{[\mathrm{g} / \mathrm{h}]}\end{array}$} & \multirow{2}{*}{$\begin{array}{c}\text { Eng_Out NOx } \\
\quad[\mathrm{g} / \mathrm{kW} . \mathrm{h}]\end{array}$} \\
\hline & & & \\
\hline Deterioration & $\mathrm{k}$ & $2.805 \mathrm{E}-05$ & $1.489 \mathrm{E}-07$ \\
\hline \multirow[t]{2}{*}{ Equation } & $\mathrm{b}$ & 1403.9 & 7.449 \\
\hline & 0 & 1403.9 & 7.449 \\
\hline \multirow[t]{2}{*}{ Odometer $[\mathrm{km}]$} & 254,622 & 1411.1 & 7.487 \\
\hline & 700,000 & 1423.6 & 7.553 \\
\hline \multicolumn{2}{|c|}{ Deterioration Factor (DF) @254,622 km } & 1.005 & 1.005 \\
\hline \multicolumn{2}{|c|}{ Deterioration Factor (DF) @ 700,000 km } & 1.014 & 1.014 \\
\hline
\end{tabular}

\section{Conclusion and Outlook}

This study had analyzed the deterioration of the engine out NOx by using $254,622 \mathrm{~km}$ durability test data and big data approach for the tested vehicle. Then, within the odometer that no engine out NOx deterioration had happened, we had completed the NOx correction for ambient temperature and humidity for NOx sensor. The main conclusions of our present study can be summarized to the following: 
- After $254,622 \mathrm{~km}$ durability test, the deterioration factor of engine out NOx is about 1.005 , which basically indicated that the engine out NOx emission was not deteriorated.

- According to the deterioration function of the engine out NOx, we forecasted that the deterioration factor of engine out NOx would be 1.014 at the end of the useful life $(700,000 \mathrm{~km})$ of the tested vehicle. That meant engine out NOx would not be deteriorated during the useful life or even longer.

- The engine out NOx concentration (ppm) would be affected by absolute humidity and ambient temperature. But, different range of absolute humidity or ambient temperature would have different effects on engine out NOx concentration (ppm).

- For a steady working condition, engine out NOx mass flow $(\mathrm{g} / \mathrm{h})$ had a good negative linear relationship with $\mathrm{Ha}\left(\mathrm{R}^{2}=0.997\right)$.

- The formula for NOx correction for ambient air temperature and humidity based on on-board sensors can be used for the deterioration analysis of the in-use vehicle engine out NOx emission.

In this work, we had only analyzed the working condition with maximum weight of the tested vehicle. Moreover, the ambient air temperature and humidity can merely represent the environmental conditions in Southeast China. As for other areas in China, the $\mathrm{k}$ and $\mathrm{b}$ in Equation 18 for calculating $K_{h, d}$ may be not suitable, it need to be proved. Future studies should focus on the applicability of $\mathrm{k}$ and $\mathrm{b}$ for different environmental conditions.

\title{
Ethics approval and consent to participate
}

\author{
Not applicable
}

\section{Consent for publication}

Not applicable

\section{Availability of data and material}

The datasets used during the current study are available from the corresponding author on reasonable request. 


\section{Competing interests}

The authors declare that they have no known competing financial interests or personal relationships that could have appeared to influence the work reported in this paper.

\section{Funding}

This research was funded by National Natural Science Foundation of China (NSFC), grant number 51679176.

\section{Authors' contributions}

Peng Li: Conceptualization, Methodology, Formal analysis, Investigation, Data Curation, Writing - Original Draft, Visualization

Lin Lü: Conceptualization, Methodology, Investigation, Resources, Writing - Review \& Editing, Supervision, Project administration, Funding acquisition

\section{Acknowledgements}

The authors are thankful to all the personnel who either provided technical support or helped with data collection. We also acknowledge all the reviewers for their useful comments and suggestions.

\section{References}

Anenberg, S.C., Miller, J., Minjares, R., Du, L., Henze, D.K., Lacey, F., Malley, C.S., Emberson, L., Franco, V., Klimont, Z., 2017. Impacts and mitigation of excess diesel-related NOx emissions in 11 major vehicle markets. Nature 545, 467-471.

Asad, U., et al. 2012. Effects of intake air humidity on the NOx emissions and performance of alightduty diesel engine. ASME 2012 Internal Combustion Engine Division Fall Technical Conference. Vancouver, BC, Canada. 235-242. https://doi.org/10.1115/ICEF2012-92027

Cheng, Y., He, L., He, W., Zhao, P., Wang, P., Zhao, J., Zhang, K., Zhang, S. 2019. Evaluating onboard sensing-based nitrogen oxides (NOx) emissions from a heavy-duty diesel truck in China. Atmospheric Environment, 216, 116908. https://doi:10.1016/j.atmosenv.2019.116908 .

China Environment News, 2020. The importance of mobile source pollution prevention is becoming increasingly prominent. URL:. http://49.5.6.212/html/2020-07/03/content 95447.htm 
De Abreu Goes, J.E., et al., 2017. Performance Studies and Correlation between Vehicle- and RapidAged Commercial Lean NOx Trap Catalysts. SAE Int. J. Engines. 10, 1613-1626.

De Abreu Goes, J., et al., 2018. Detailed Characterization Studies of Vehicle and Rapid Aged Commercial Lean NOx Trap Catalysts. Industrial \& Engineering Chemistry Research. 57, 9362-9373.

Deng, F., et al. 2020. A big data approach to improving the vehicle emission inventory in China. Nat Commun. 11, 2801. https://doi.org/10.1038/s41467-020-16579-w

Economic Commission for Europe of the United Nations, 2010. Regulation No 49 of the Economic Commission for Europe of the United Nations (UN/ECE) - Uniform provisions concerning the measures to be taken against the emission of gaseous and particulate pollutants from compression-ignition engines for use in vehicles, and the emission of gaseous pollutants from positive-ignition engines fuelled with natural gas or liquefied petroleum gas for use in vehicles. Official J. European Union 2010 L 229/1.

European Commission, 2011. Commission regulation (EU) No 582/2011 of 25 may 2011 implementing and amending regulation (EC) No 595/2009 of the European parliament and of the council with respect to emissions from heavy duty vehicles (Euro VI) and amending annexes I and III to directive 2007/46/EC of the European parliament and of the council. Official J. European Union 2011 L 167/1.

GB 17691-2018. Limits and measurement methods for emissions from diesel fueled heavy-duty vehicles (CHINA VI) [S]. Ministry of Ecology and Environment of the People's Republic of China.

Grange, S.K., Lewis, A.C., Moller, S.J., Carslaw, D.C., 2017. Lower vehicular primary emissions of NO2 in Europe than assumed in policy projections. Nat. Geosci. 10, 914-918.

Hiromi Kondoh, et al., 1991. Some Correction Factors for Application to stationary Diesel Engine NOx Data. Journal of the M.E.S.J.

Krause, S. R., et al., 1974.Effect of Inlet Air Humidity and Temperature on Diesel Exhaust Emissions. SAE TRANSACTIONS.730213, 831.

Liu, B., Lü, L. 2015. Research on NOx emission Alarm Caused by the Intake-Air Relative Humidity for Truck Diesel engines. Chinses Internal Combustion Engine Engineering. 36, 6. 
Luengo J., García-Gil D., Ramírez-Gallego S., García S., Herrera F. 2020. Introduction. In: Big Data Preprocessing. Springer, Cham. https://doi.org/10.1007/978-3-030-39105-8_ 1

Ma, J., et al. 2020. Identification of high impact factors of air quality on a national scale using big data and machine learning techniques. Journal of Cleaner Production. 244,118955.

McCoy, B.J. and A. Tanman, 2014. Emissions Performance and In-Use Durability of Retrofit AfterTreatment Technologies. SAE International Journal of Engines.7, 1637-1649.

Pekula, N., 2003.The Effect of Ambient Temperature, Humidity, and Engine Speed on Idling Emissions from Heavy-Duty Diesel Trucks, SAE International.

Schmieg, S.J., et al., 2012. Thermal durability of Cu-CHA NH3-SCR catalysts for diesel NOx reduction. Catalysis Today. 184, 252-261.

Steffen, B., et al., 2020. Big Data Analytics for the Connected and Automated Vehicle. ATZ Worldw. 122, 36-41. https://doi.org/10.1007/s38311-019-0158-4

Wu, Y., Zhang, S., Hao, J., Liu, H., Wu, X., Hu, J., Walsh, M.P., Wallington, T.J., Zhang, K.M., Stevanovic, S., 2017. On-road vehicle emissions and their control in China: a review and outlook. Sci. Total Environ. 574, 332-349.

Wang, Z., et al. 2018. Effect of Ambient Humidity on NO x and Soot Emissions in a Diesel Engine. Transactions of CSICE. 36, 4. DOI: 10.16236/j.cnki.nrjxb.201804042.

Wang L., Huang, Z. 2019. Research on the Sensitivity of NOx emission for diesel engines to intake air humidity. Internal Combustion Engine \& Powerplant. 36, 29-34. DOI:10.19471/j.cnki.1673-6397.2019.01.006

Zhang, Y., et al., 2018. Experimental study on the durability of biodiesel-powered engine equipped with a diesel oxidation catalyst and a selective catalytic reduction system. Energy. 159, 10241034. 
Figures
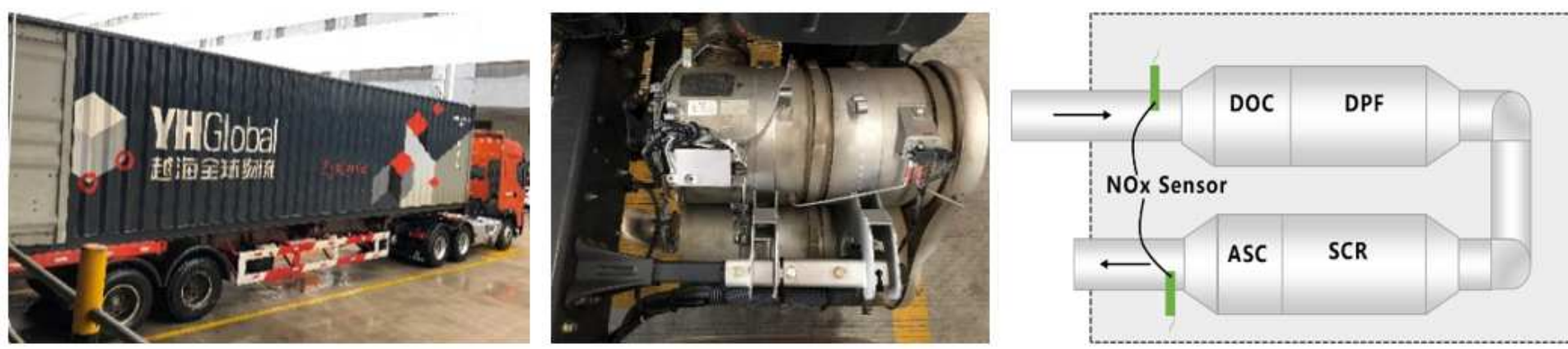

Figure 1

(a) Tested vehicle; (b) aftertreatment configuration (picture of real products); (c) NOx sensors location and aftertreatment configuration (schematic plot).

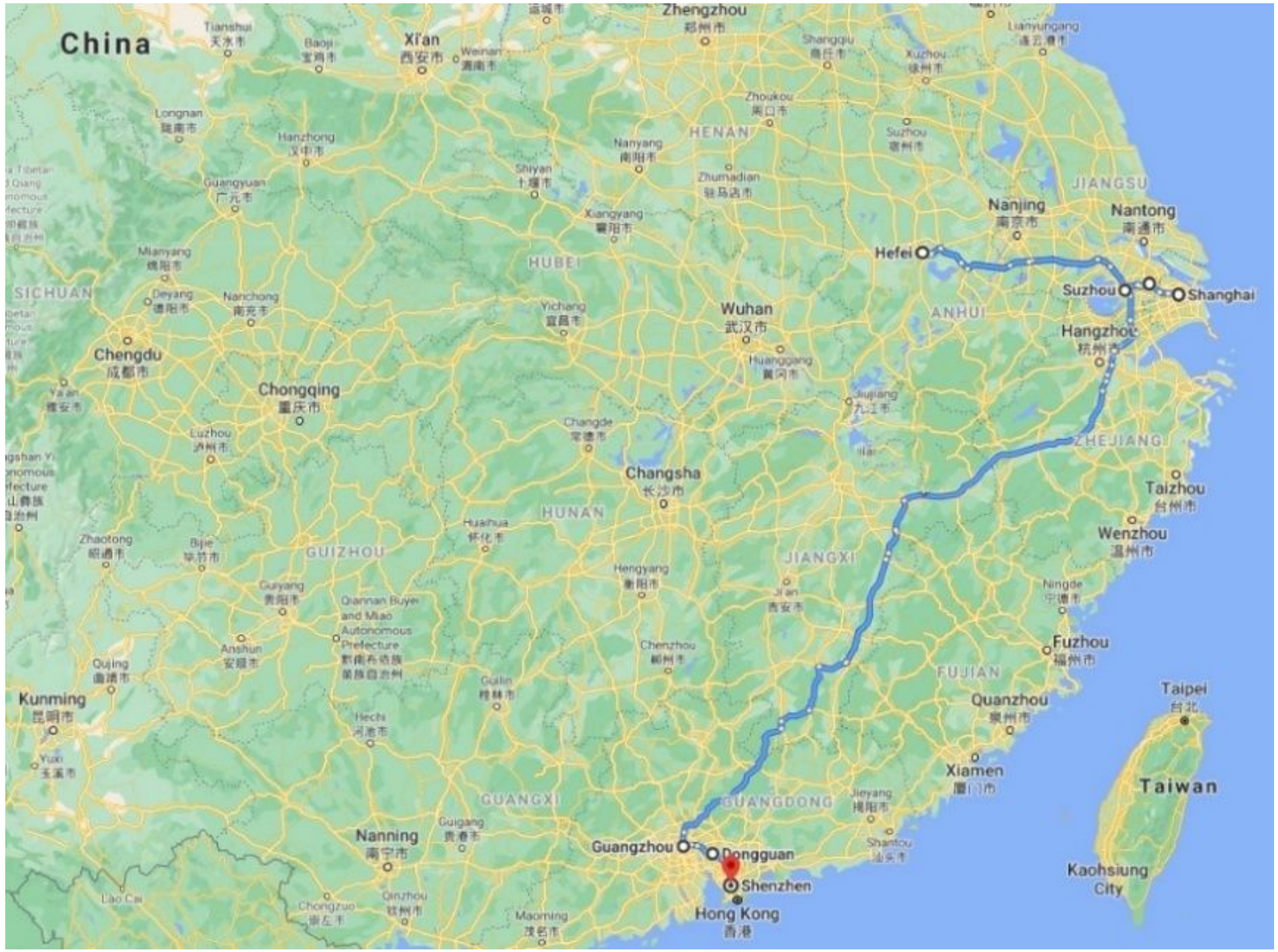

Figure 2 
The main operating route of the tested vehicle Note: The designations employed and the presentation of the material on this map do not imply the expression of any opinion whatsoever on the part of Research Square concerning the legal status of any country, territory, city or area or of its authorities, or concerning the delimitation of its frontiers or boundaries. This map has been provided by the authors.

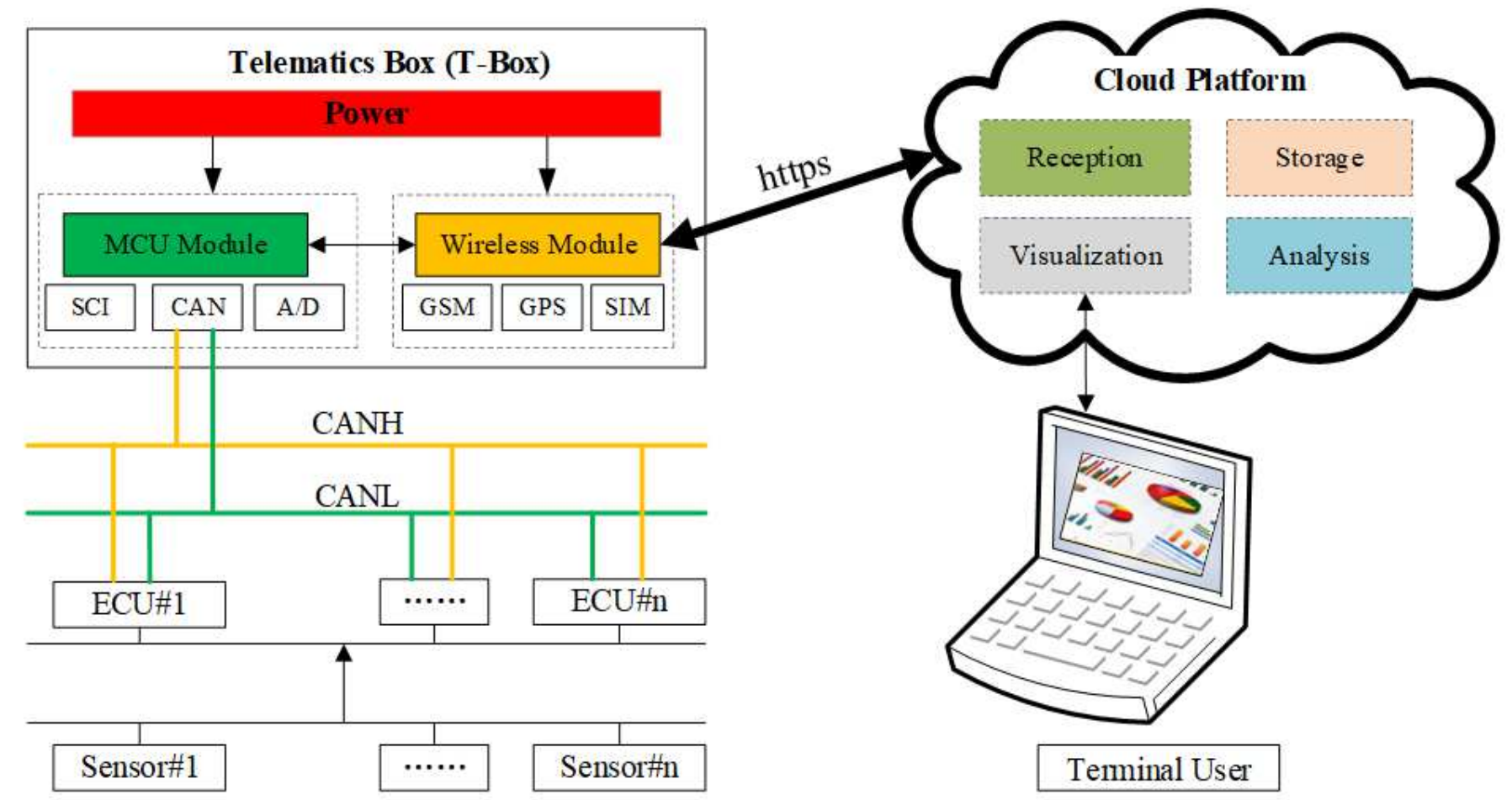

\section{Figure 3}

Data Acquisition System (schematic plot) 


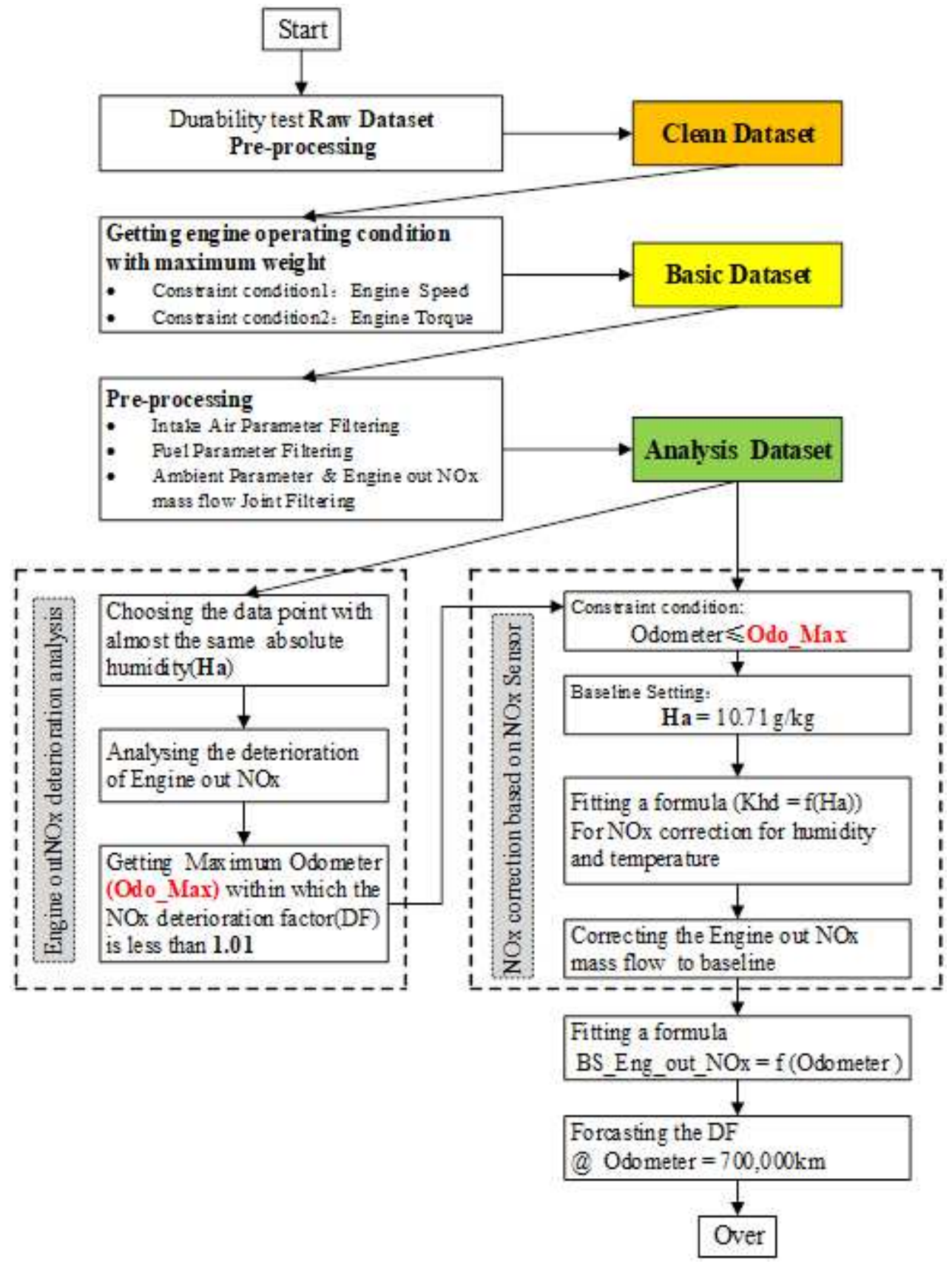

Figure 4

Method of engine out NOx deterioration analysis 


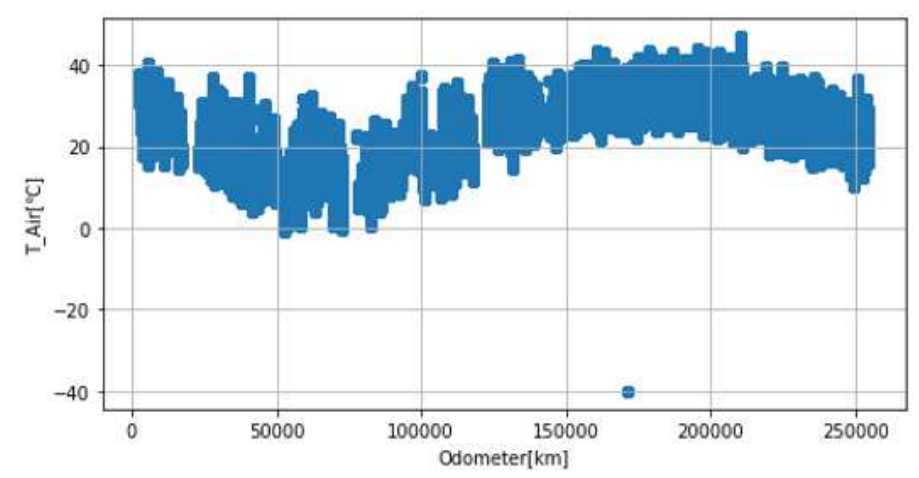

(a) Before preprocessing

\section{Figure 5}

Method of engine out NOx deterioration analysis

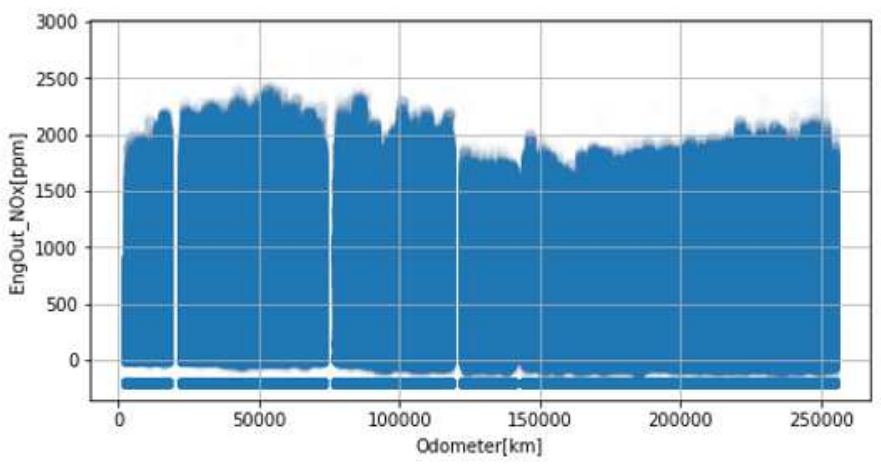

(a) Before preprocessing

\section{Figure 6}

Demo for unmodifiable outliers preprocessing

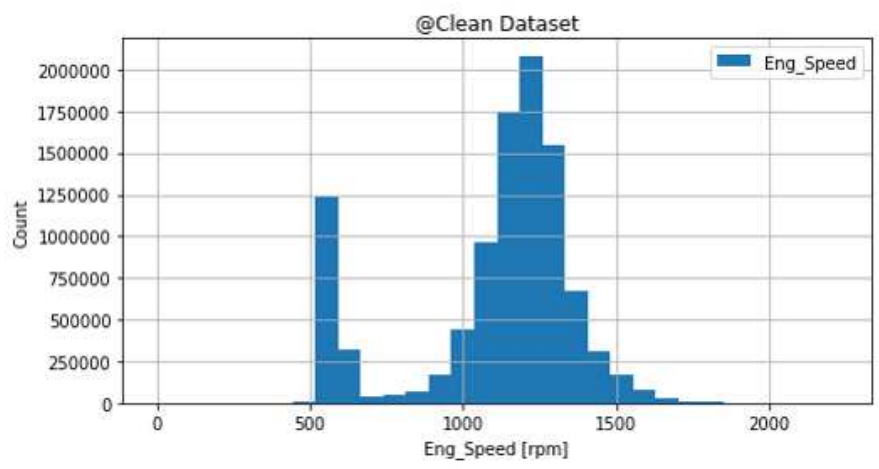

(a)

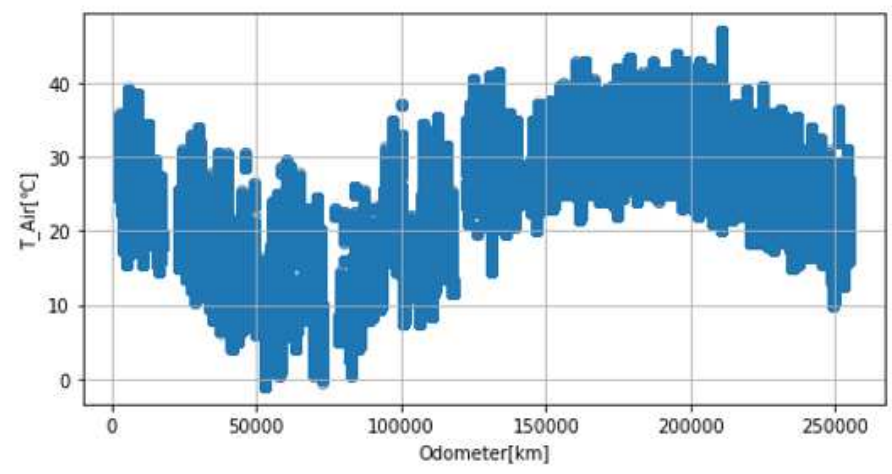

(b) After preprocessing

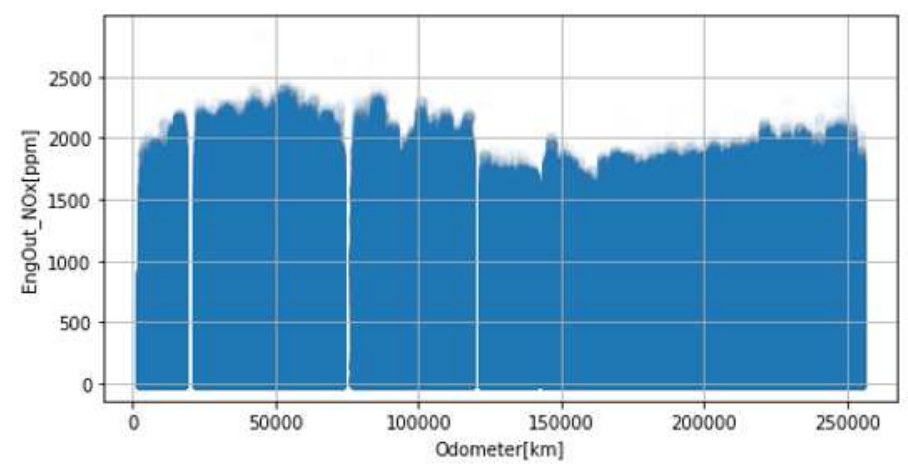

(b) After preprocessing

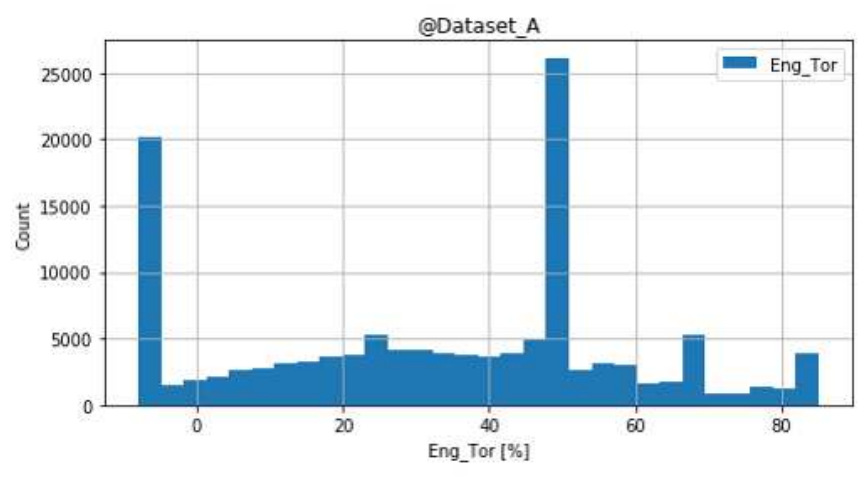

(b) 
Figure 7

(a) Eng_Speed distribution @ Clean Dataset; (b) Eng_Tor distribution @ Dataset_A

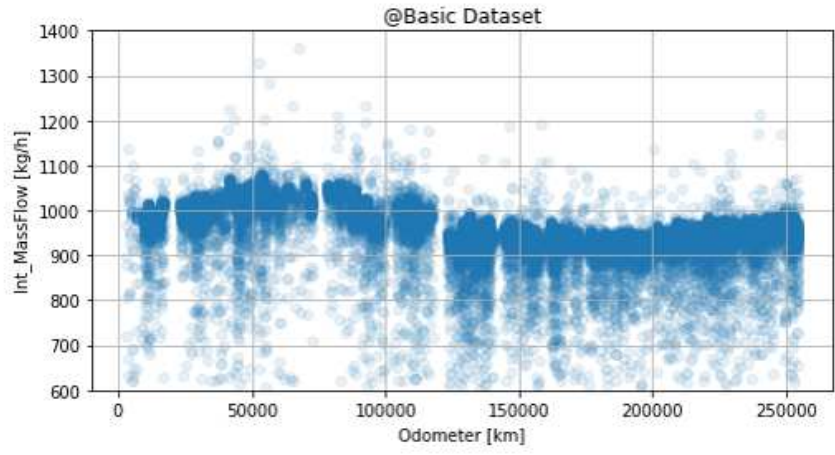

(a)

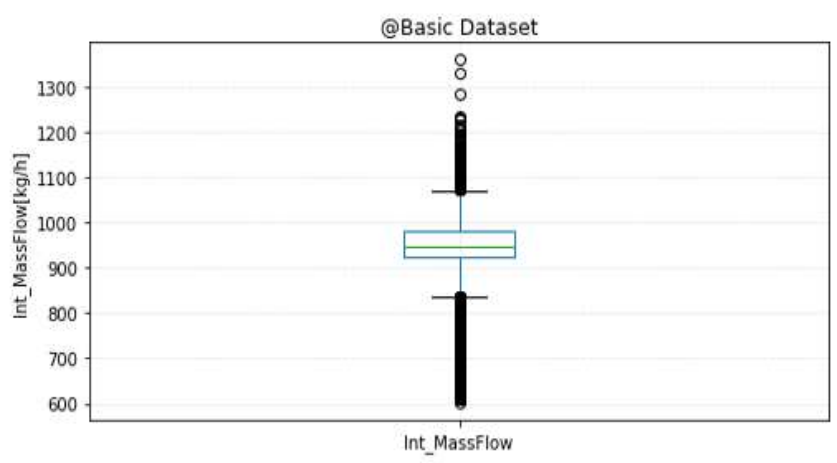

(c)

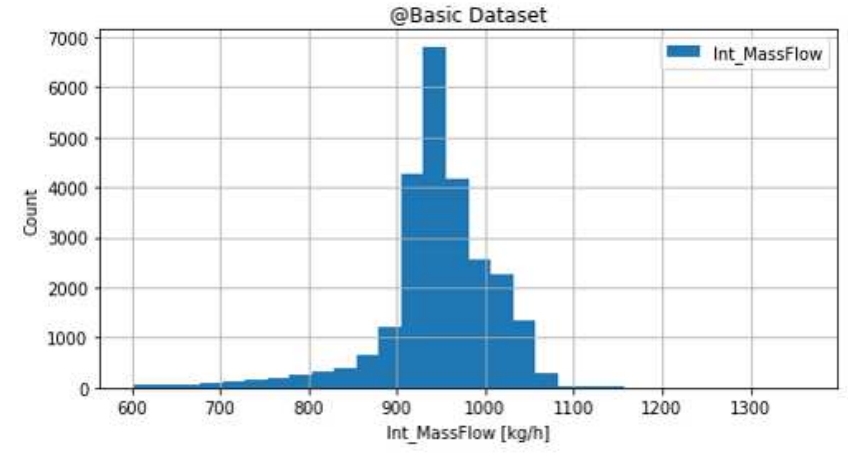

(b)

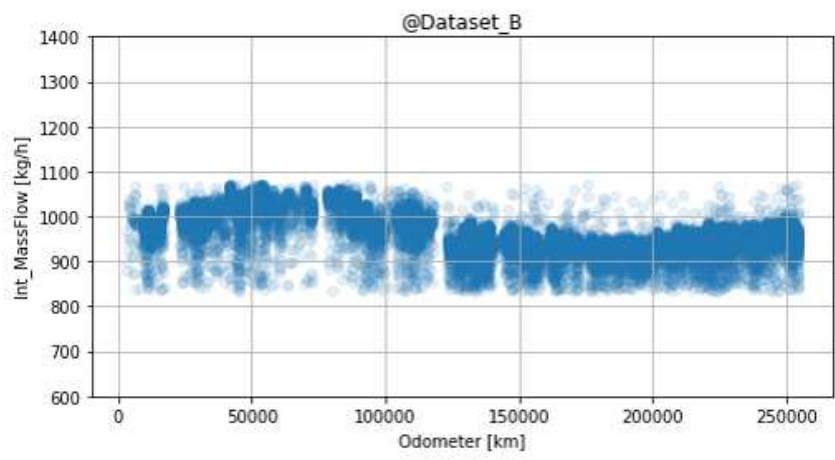

(d)

\section{Figure 8}

Intake air parameter filtering. (a) Int_MassFlow vs odometer @ Basic Dataset; (b) Int_MassFlow frequency distribution @ Basic Dataset; (c) Int_MassFlow box-plot @ Basic Dataset; (d) Int_MassFlow vs odometer @ Dataset_B; 


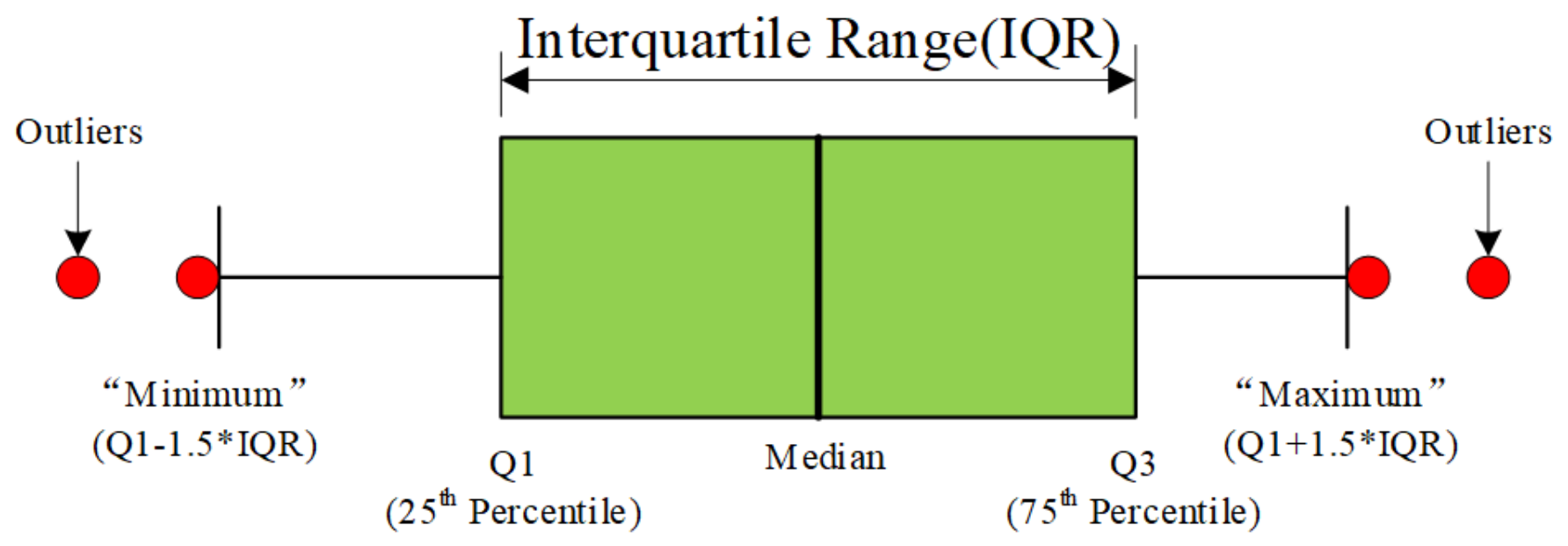

Figure 9

IQR (box-plot) filtering schematic plot 


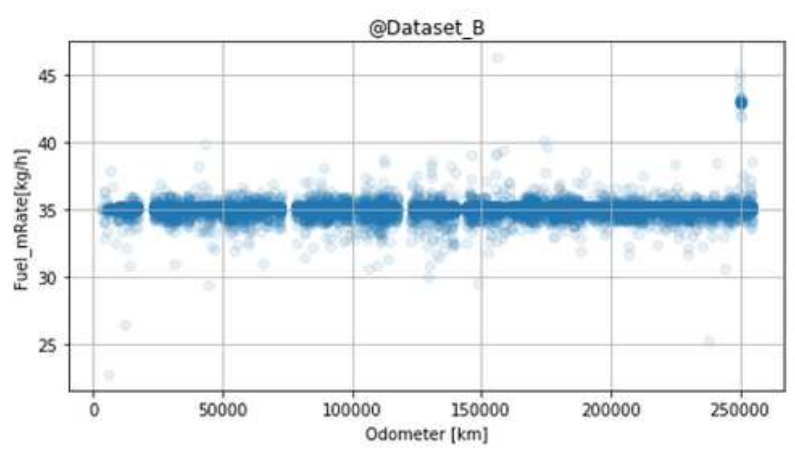

(a)

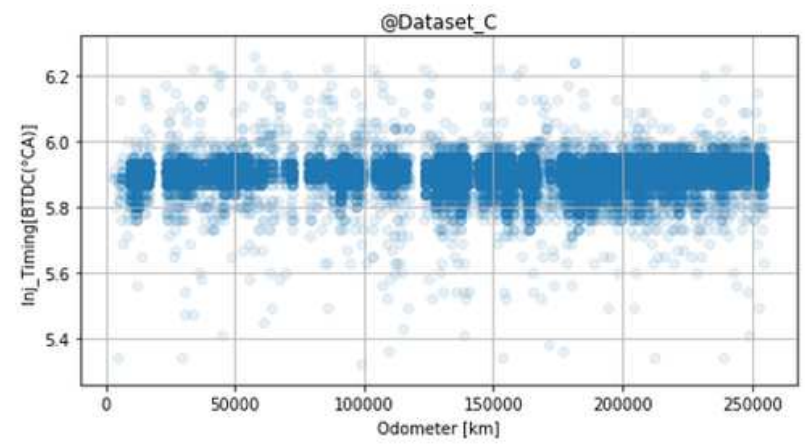

(c)

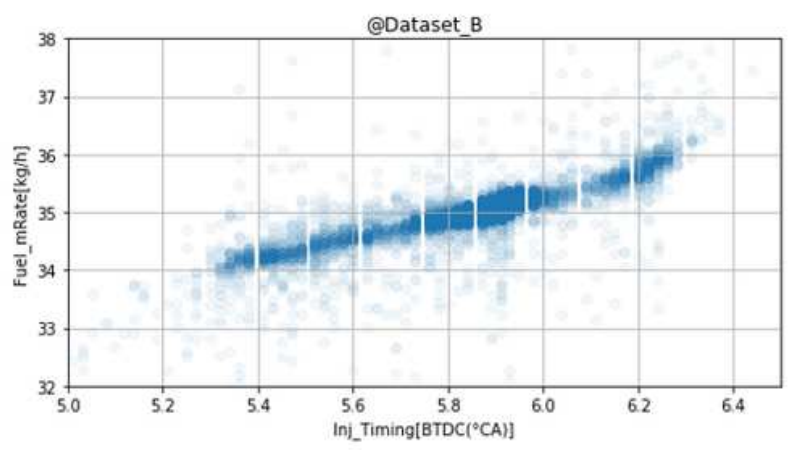

(e)

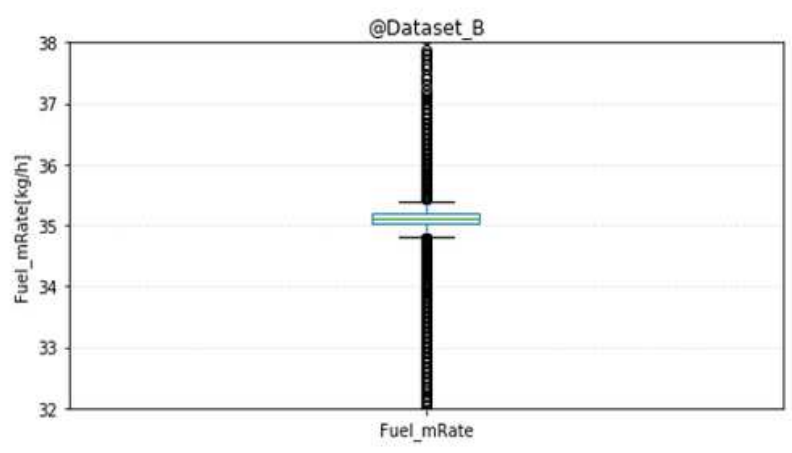

(b)

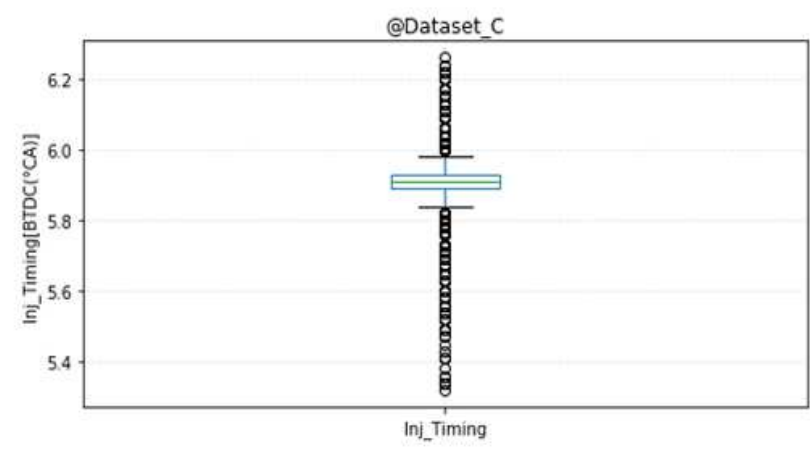

(d)

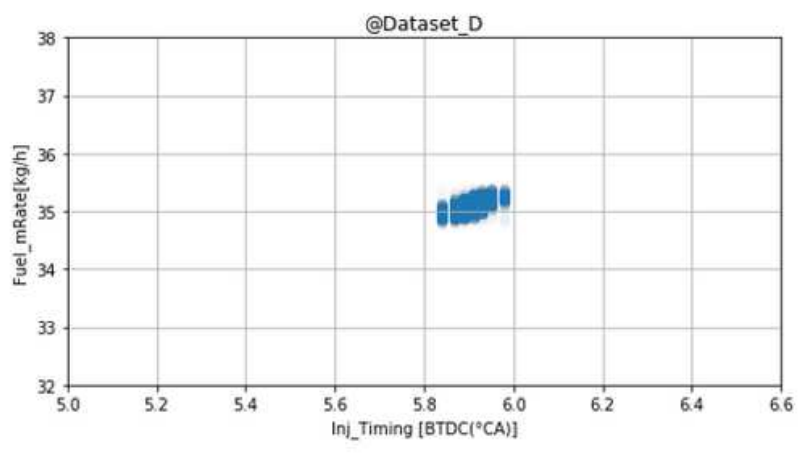

(f)

\section{Figure 10}

Fuel injection parameters filtering (a) Fuel_mRate vs odometer @ Dataset_B; (b) Fuel_mRate box-plot @ Dataset_B; (c) Inj_Timing vs odometer @ Dataset_C; (d) Inj_Timing box-plot @ Dataset_C ; (e) Inj_Timing vs Fuel_mRate @ Dataset_B; (f) Inj_Timing vs Fuel_mRate @ Dataset_D; 


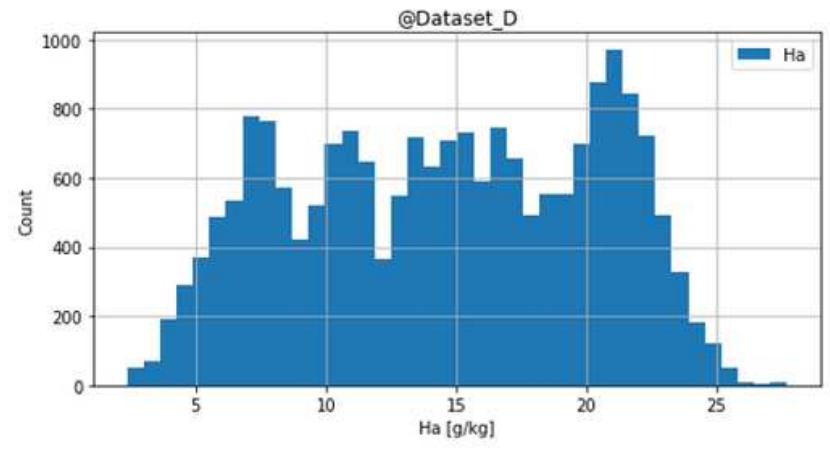

(a)

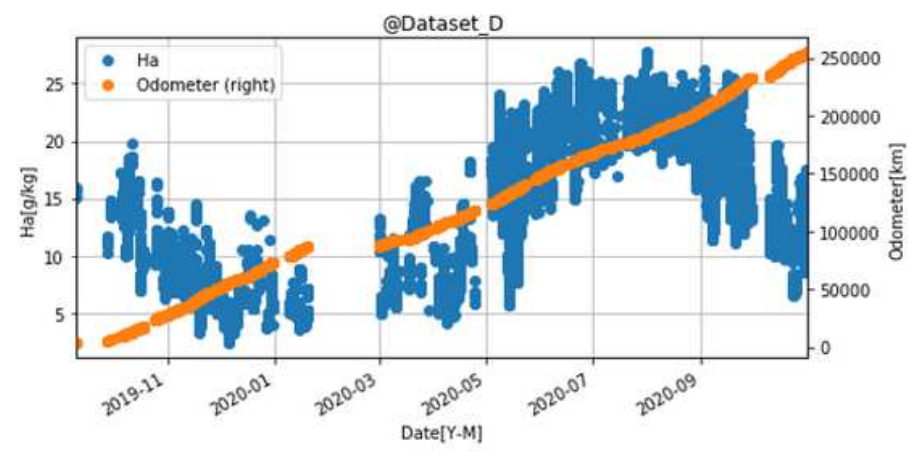

(b)

\section{Figure 11}

(a) Ha distribution@ Dataset_D; (b) Ha \& odometer vs Date @ Dataset_D

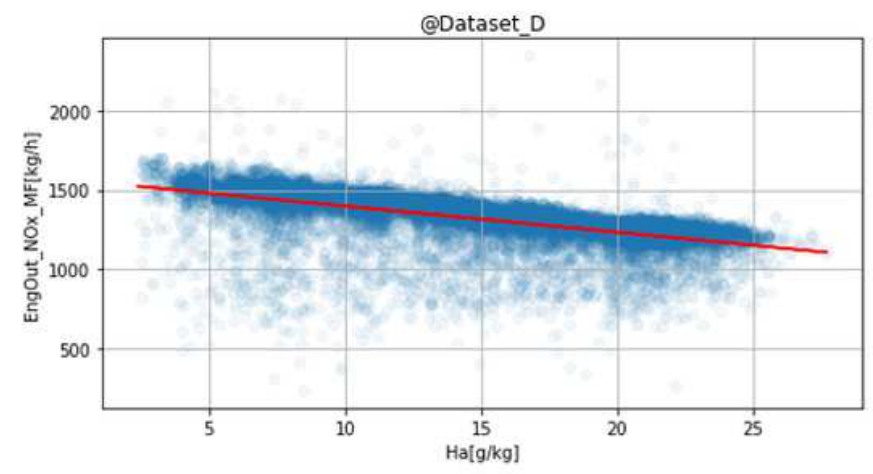

(a)

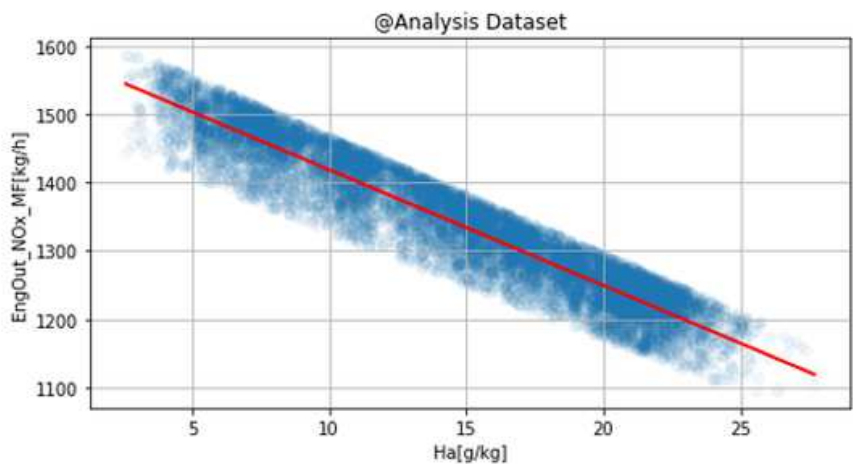

(b)

\section{Figure 12}

Ambient parameters and engine out NOx mass flow joint filtering; (a) Ha vs EngOut_NOx_MF@ Dataset_D; (b) Ha vs EngOut_NOx_MF@ Analysis Dataset;

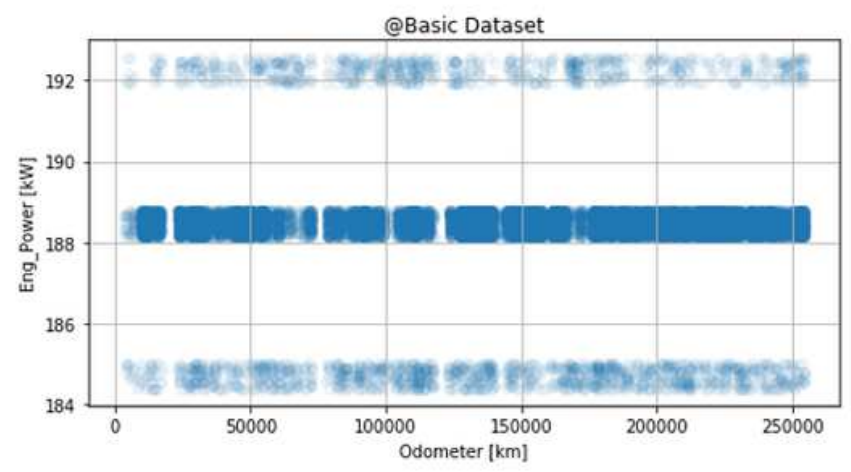

(a)

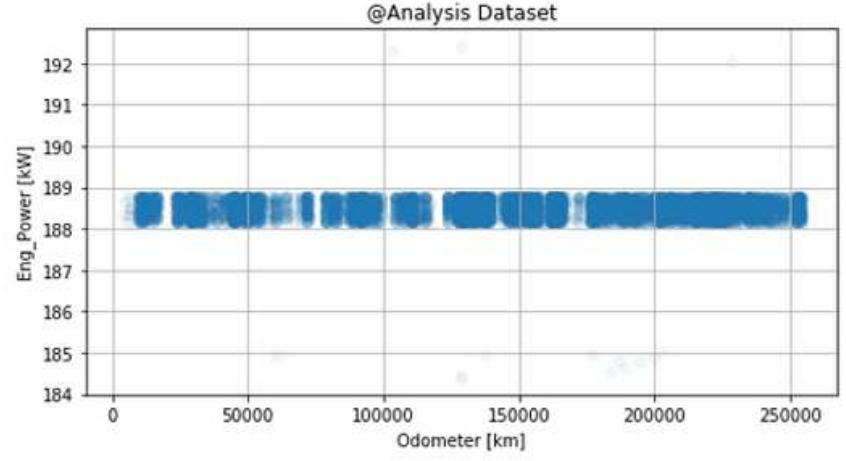

(b) 
Figure 13

(a) Eng_Power vs Odometer @ Basic Dataset; (b) Eng_Power vs Odometer@ Analysis Dataset;

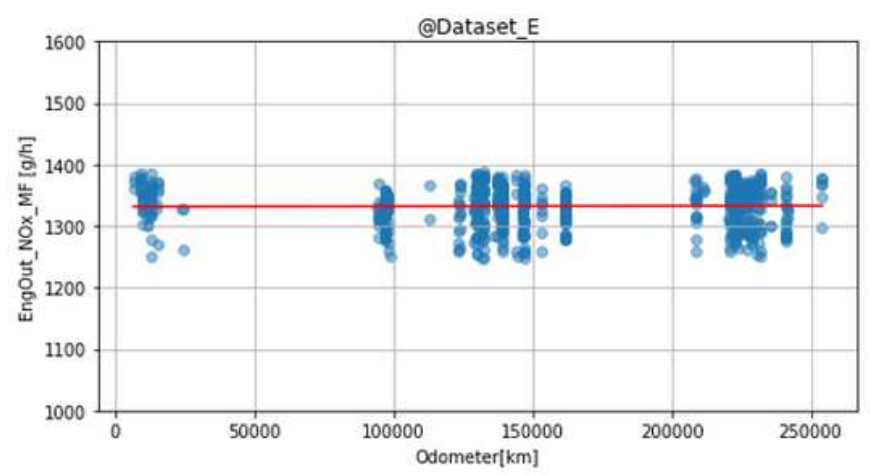

(a)

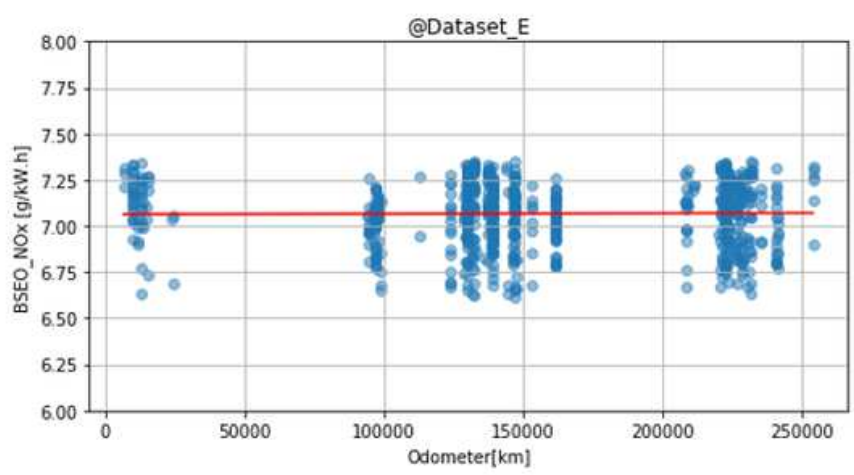

(b)

Figure 14

(a) EngOut_NOx_MF vs Odometer @ Dataset_E; (b) BSEngOut_NOx vs Odometer@ Dataset_E;

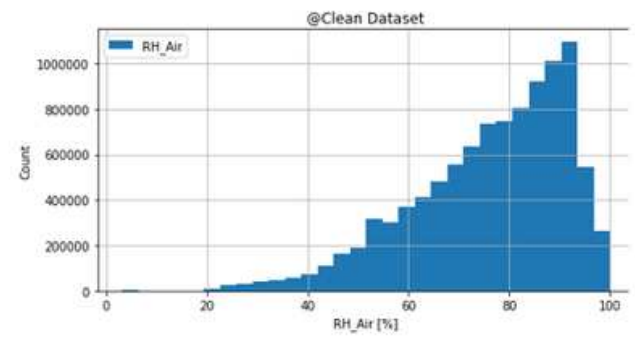

(a)

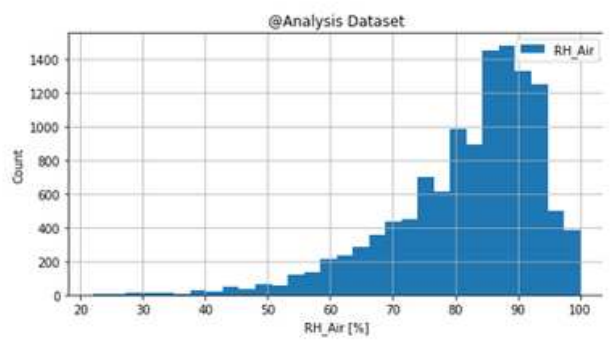

(b)

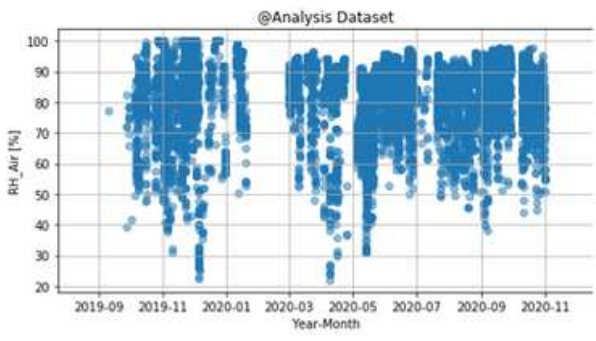

(c)

\section{Figure 15}

(a) RH_Air distribution @Clean Dataset; (b) RH_Air distribution @Analysis Dataset; (c) RH_Air vs Date @ Analysis Dataset

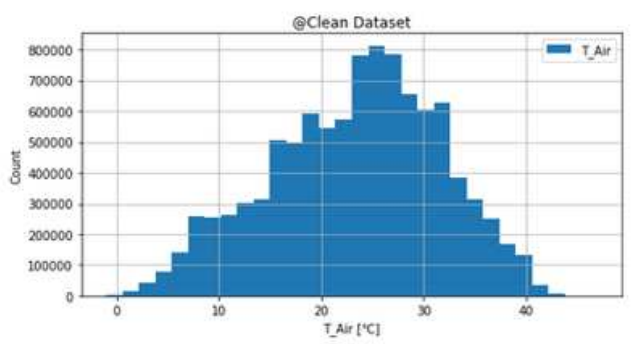

(a)

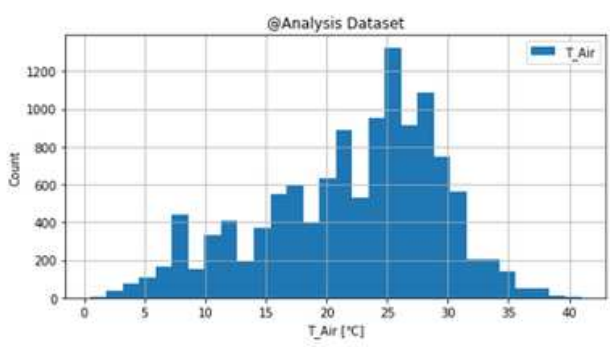

(b)

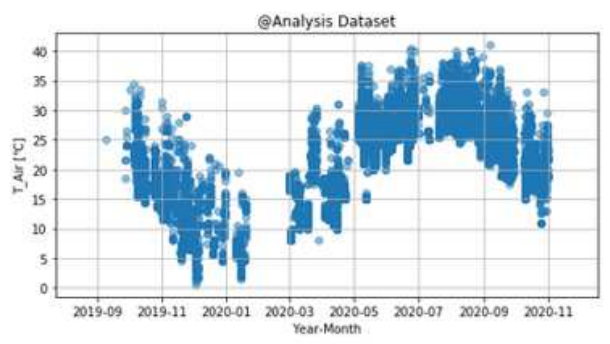

(c) 
Figure 16

(a) T_Air distribution @Clean Dataset; (b) T_Air distribution @Analysis Dataset; (c) T_Air vs Date @ Analysis Dataset

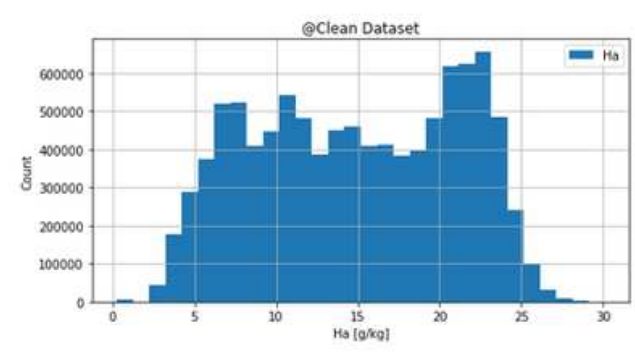

(a)

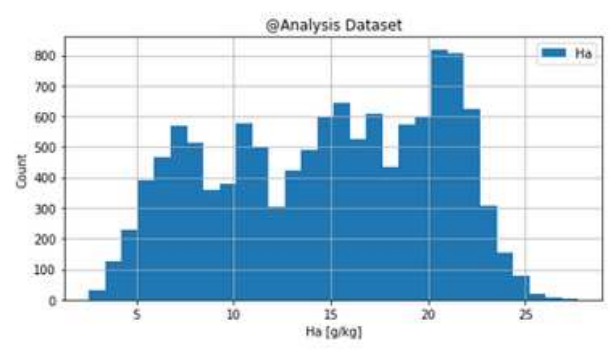

(b)

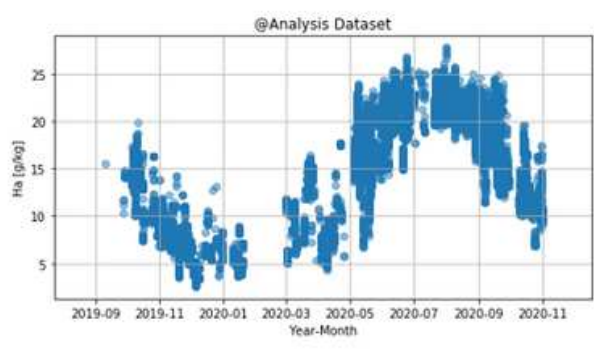

(c)

\section{Figure 17}

(a) Ha distribution @Clean Dataset; (b) Ha distribution @Analysis Dataset; (c) Ha vs Date @ Analysis Dataset

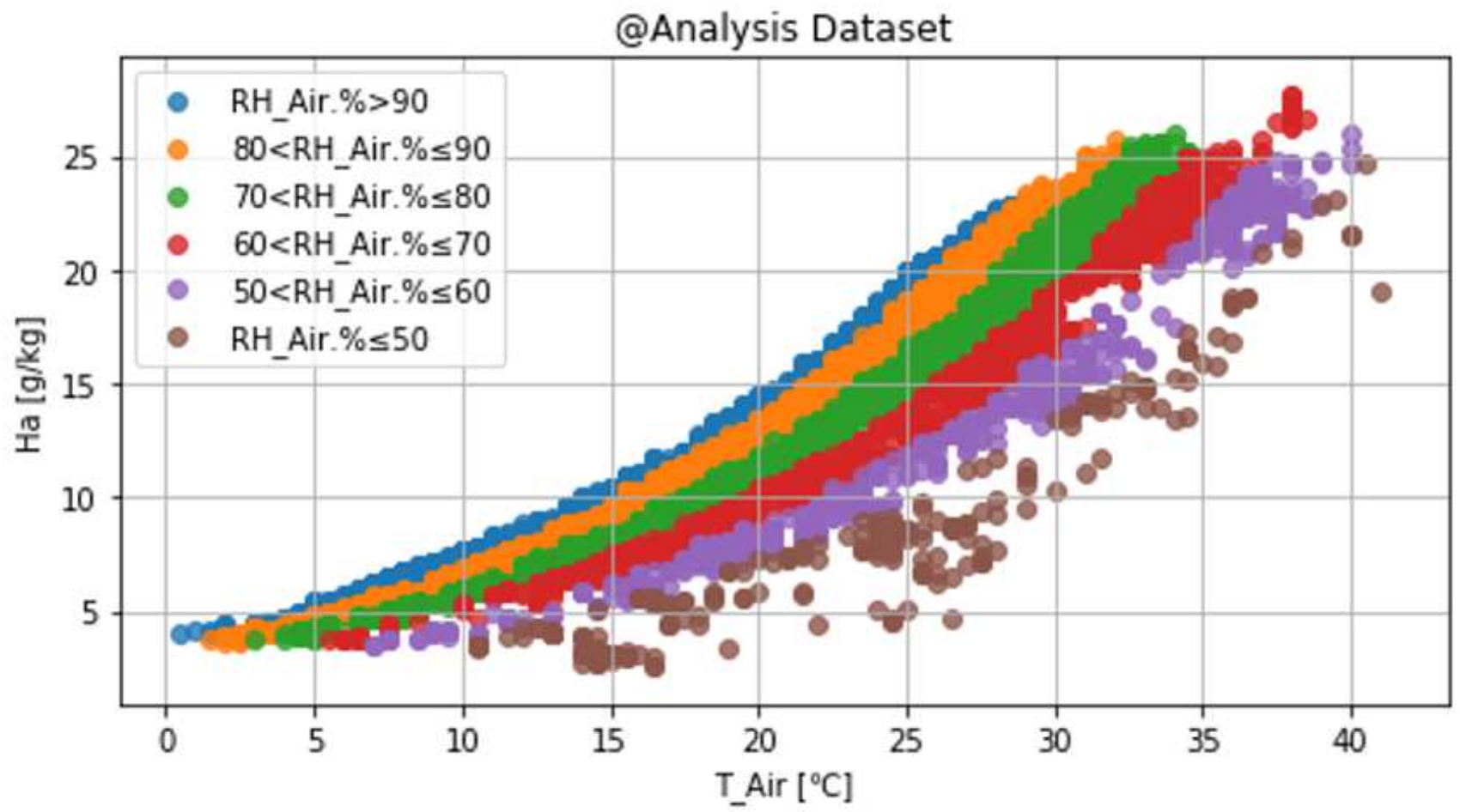

Figure 18

The relationship between $\mathrm{Ha}$ and ambient temperature/relative humidity 


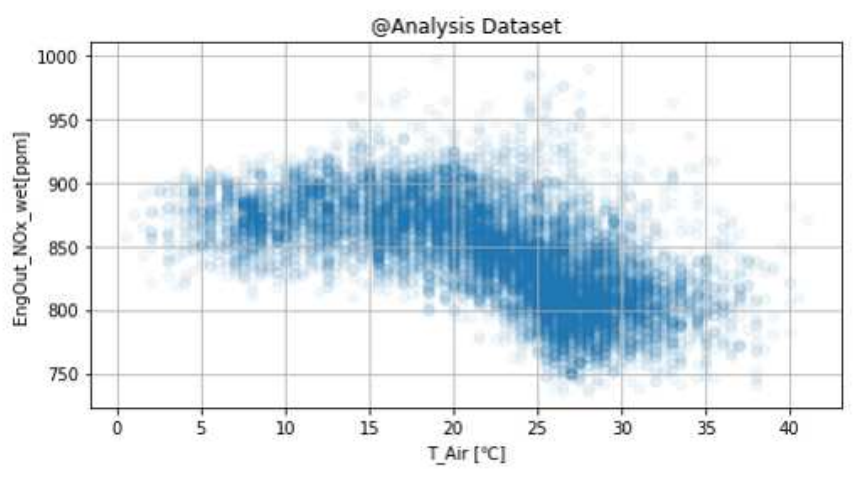

(a)

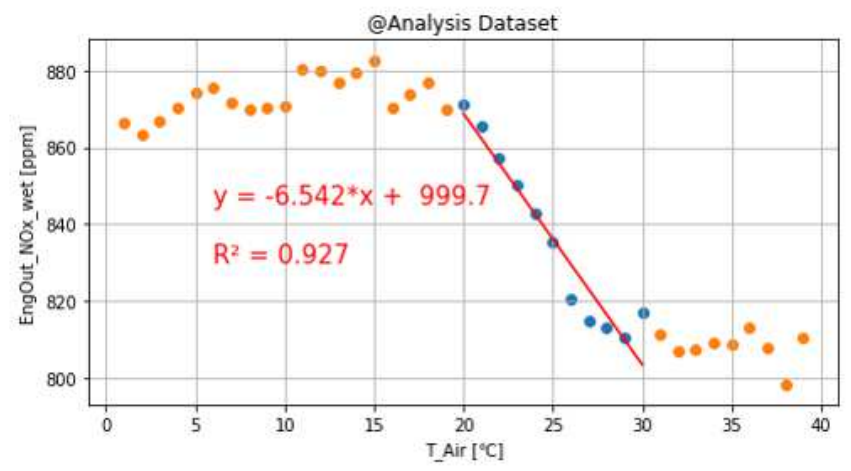

(b)

\section{Figure 19}

(a) T_Air vs EngOut_NOx_wet @ Analysis Dataset; (b) T_Air vs EngOut_NOx_wet (mean) @ Analysis Dataset;

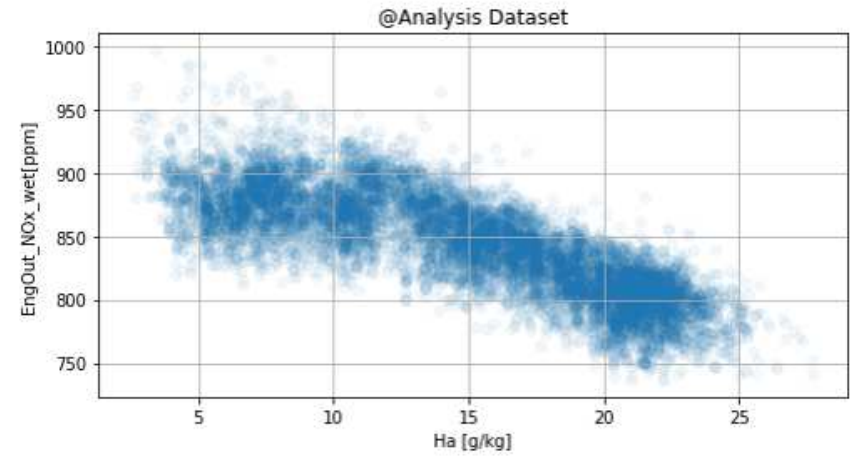

(a)

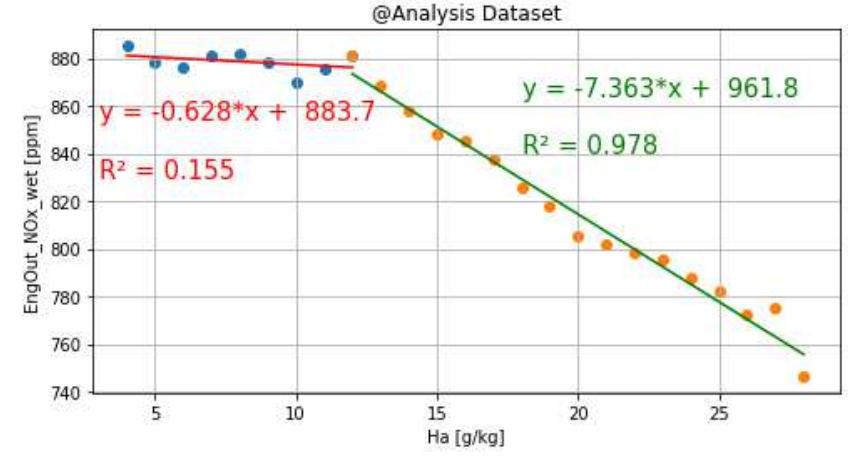

(b)

Figure 20

(a) T_Air vs EngOut_NOx_wet @ Analysis Dataset; (b) T_Air vs EngOut_NOx_wet (mean) @ Analysis Dataset;

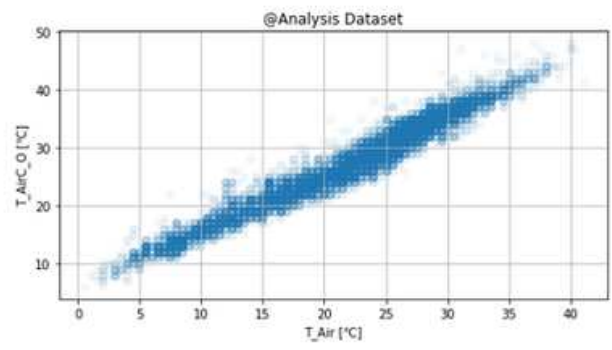

(a)

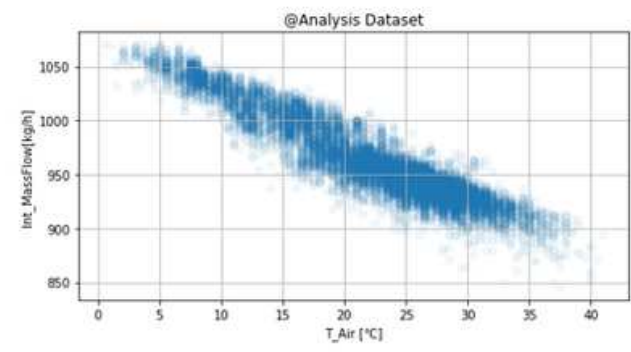

(b)

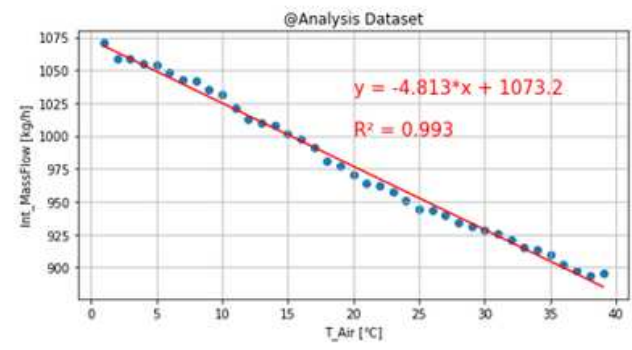

(c) 
Figure 21

(a) T_Air vs T_AirC_0 @ Analysis Dataset; (b) T_Air vs Int_MassFlow @ Analysis Dataset; (c) T_Air vs Int_MassFlow (mean) @ Analysis Dataset

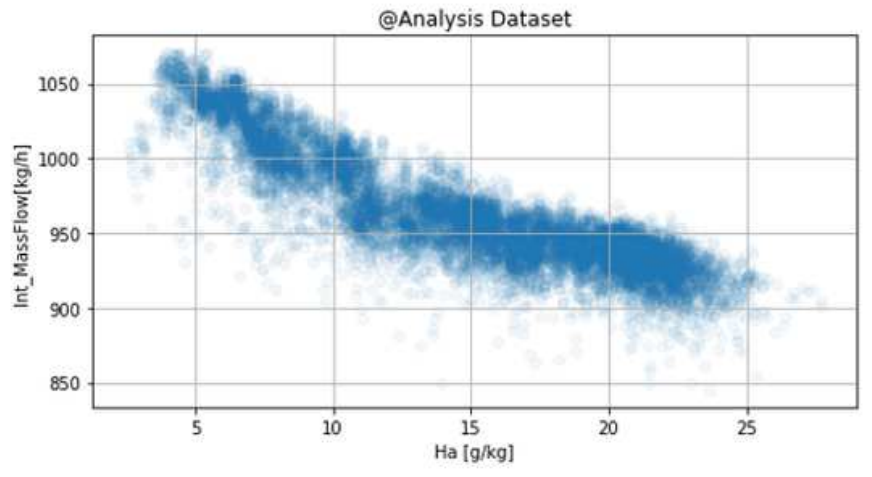

(a)

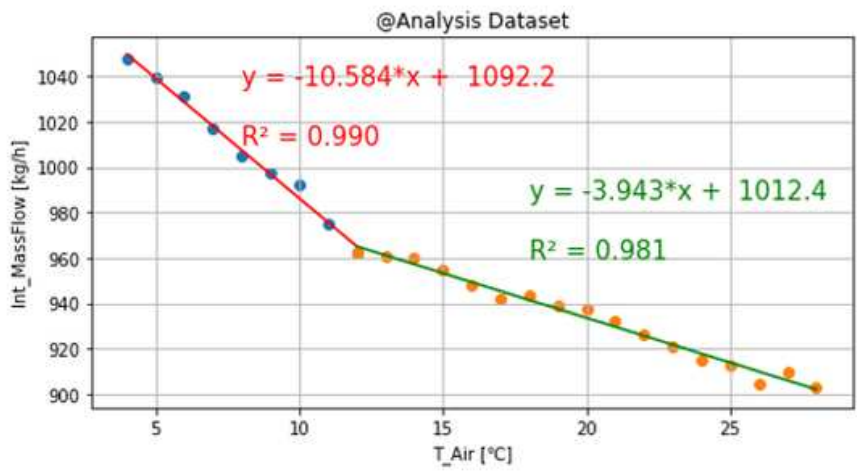

(b)

\section{Figure 22}

(a) Ha vs Int_MassFlow @ Analysis Dataset; (b) Ha vs Int_MassFlow (mean) @ Analysis Dataset.

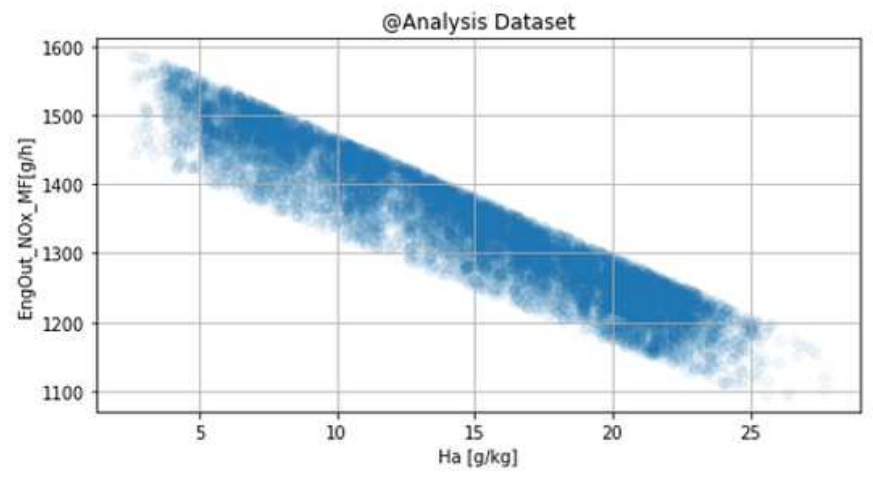

(a)

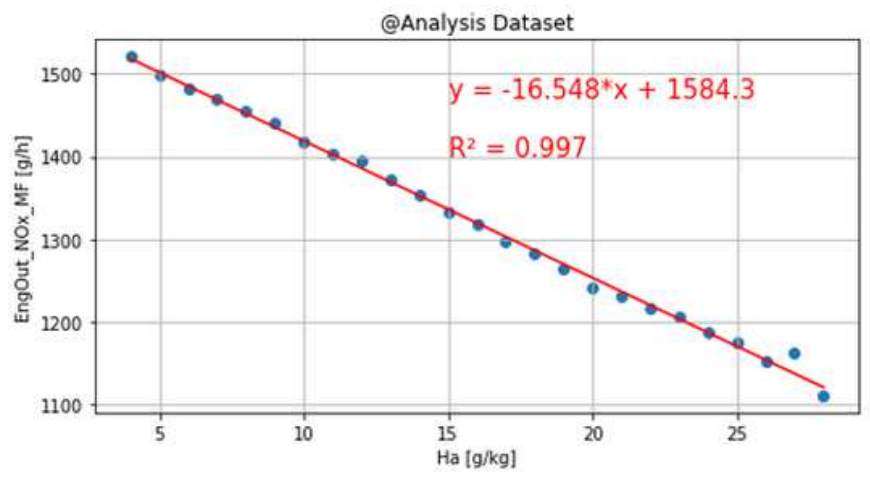

(b)

\section{Figure 23}

(a) Ha vs EngOut_NOx_MF@ Analysis Dataset; (b) Ha vs EngOut_NOx_MF (mean) @ Analysis Dataset; 


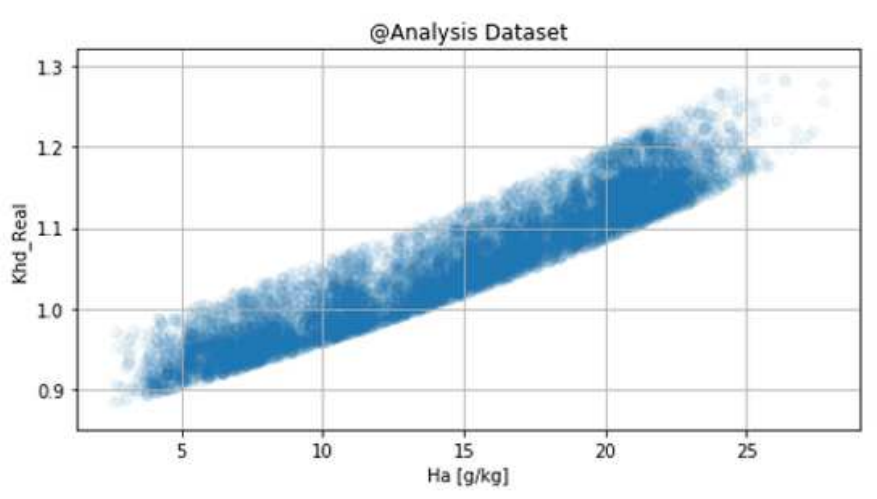

(a)

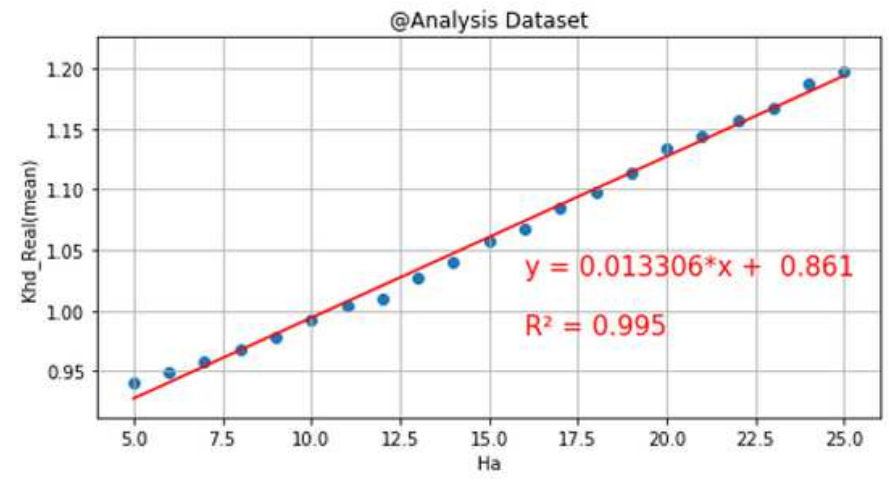

(b)

\section{Figure 24}

(a) Ha vs Kh,d_Real @ Analysis Dataset; (b) Ha vs Kh,d_Real (mean) @ Analysis Dataset;

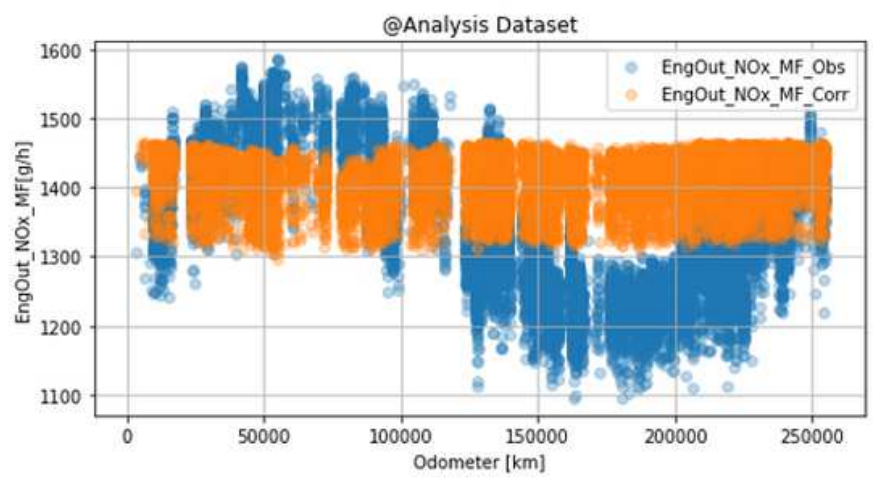

(a)

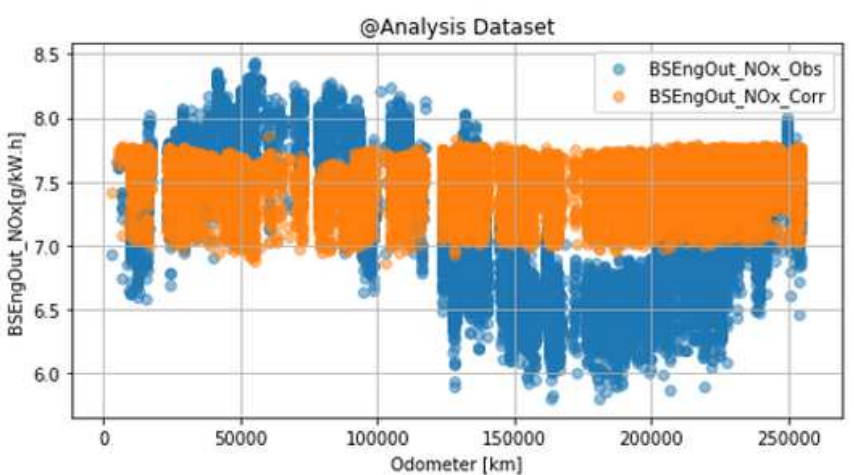

(b)

\section{Figure 25}

(a) Odometer vs EngOut_NOx_MF @ Analysis Dataset; (b) Odometer vs BSEngOut_NOx @ Analysis Dataset; 